\title{
Recent advances on the construction of diarylethene-based supramolecular metallacycles and metallacages via coordination-driven self- assembly
}

\author{
Yi Qin ${ }^{1, \#}$, Yu-Te Wang ${ }^{1, \#}$, Hai-Bo Yang ${ }^{1, *}$, Weihong Zhu ${ }^{2, *}$ \\ 'Shanghai Key Laboratory of Green Chemistry and Chemical Processes, School of Chemistry and Molecular Engineering, East \\ China Normal University, Shanghai 200241, China. \\ ${ }^{2}$ State Key Laboratory of Bioreactor Engineering, Shanghai Key Laboratory of Functional Materials Chemistry, Institute of Fine \\ Chemicals, School of Chemistry and Molecular Engineering, East China University of Science \& Technology, Shanghai 200237, \\ China. \\ \#Authors contributed equally.
}

*Correspondence to: Prof. Hai-Bo Yang, School of Chemistry and Molecular Engineering, East China Normal University, 3663 N. Zhongshan Road, Shanghai 200241, China. E-mail: hbyang@chem.ecnu.edu.cn; Prof. Weihong Zhu, State Key Laboratory of Bioreactor Engineering, Shanghai Key Laboratory of Functional Materials Chemistry, Institute of Fine Chemicals, School of Chemistry and Molecular Engineering, East China University of Science \& Technology, Meilong Road 130, Shanghai 200237, China.E-mail: whzhu@ecust.edu.cn

How to cite this article: Qin Y, Wang YT, Yang HB, Zhu W. Recent advances on the construction of diarylethene-based supramolecular metallacycles and metallacages via coordination-driven self-assembly. Chem Synth 2021;1:2.

https://dx.doi.org/10.20517/cs.2021.05

Received: 15 Jun 2021 First Decision: 1 Jul 2021 Revised: 3 Jul 2021 Accepted: 6 Jul 2021 First online: 8 Jul 2021

Academic Editor: Bao-Lian Su Copy Editor: Xi-Jun Chen Production Editor: Xi-Jun Chen

\begin{abstract}
During the past few years, the construction of diarylethene (DAE)-based supramolecular metallacycles and metallacages has gained increasing attention due to their distinctive photophysical and photochemical properties and potential applications in magnetic switching, smart soft materials, photodynamic therapy, etc. Surprisingly, no review on the construction of discrete DAE-based supramolecular metallacycles and metallacages via coordination-driven self-assembly has been summarized to the best of our knowledge. Considering the rapid development of this field, it is time to summarize the recent development of the construction of discrete DAEcontaining polygons and polyhedra. In this review, the construction of diarylethene-based metallacycles and metallacages via coordination-driven self-assembly is briefly introduced. In addition, the properties and applications of these metallacycles and metallacages are also discussed.
\end{abstract}


Keywords: Diarylethene, metallacycles and metallacages, coordination-driven self-assembly, photochromism

\section{INTRODUCTION}

Coordination-driven self-assembly has proven to be a powerful synthetic strategy for the construction of discrete supramolecular coordination complexes (SCCs) including two-dimensional (2D) polygons and three-dimensional (3D) polyhedral ${ }^{[1-8]}$. Due to the synthetic convenience, during the past few decades, various metallacycles and metallacages with well-defined shapes and sizes have been successfully prepared and have displayed widespread applications in molecular sensing, catalysis, drug delivery and biological applications ${ }^{[9-17]}$. In particular, the construction of stimuli-responsive metallacycles and metallacages has attracted increasing interest because of their potential applications in smart materials, molecular machine and so on, which further promotes the development of supramolecular chemistry and materials science ${ }^{[18-23]}$.

Diarylethenes, the derivatives of stilbene, are a kind of typical photochromic species ${ }^{[24]}$. Under UV irradiation, the diarylethene molecules change from colorless to colored state, whereas the colors disappear under visible light irradiation. Different from the traditional $\mathrm{T}$ type photochromic molecules (thermally reversible) such as azobenzene and spiropyran, both isomers of diarylethenes (ring-open form and ringclosed form) are stable and the photogenerated isomers (ring-closed form) hardly return to the ring-open form in the dark, which could be classified into P type photochromic molecules (thermally irreversible, but photochemically reversible). As shown in Scheme 1, the $\pi$-conjugation of the ring-open form diarylethene molecule is localized in the thiophene ring, whereas, in the ring-closed form state, the $\pi$-conjugation delocalizes throughout the molecule, thus resulting in its electronic structure changes as well as its geometrical structure changes. Due to their interesting photophysical properties such as high photoconversion yield, high thermal stability of both isomers, excellent fatigue-resistant property and rapid response, many diarylethene molecules with structural diversity have been synthesized during the past few decades and have exhibited extensive applications in molecular switches, optical memories and molecular machines ${ }^{[25-27]}$.

Since diarylethenes show excellent photophysical and photochemical properties, integrating diarylethene subunits into a supramolecular coordination complex may lead to unique properties and functions: (1) diarylethenes could endow the metallacycles or metallacages with photoresponsive property, thereby offering the possibility for photoresponsive guest encapsulation/release and photo-controlled supramolecular transformation; (2) the metallacycles or metallacages could regulate the photochromic property of diarylethenes through the formation of coordination bond, such as the increased photoconversion yield and the enhanced fatigue-resistant property; and (3) taking advantage of the welldefined skeleton of both metallacycles and metallacages, the efficient photo-controlled energy transfer could be realized through the integration of diarylethene and other functional subunits into one entity. In recent decades, chemists have designed and prepared a series of diarylethene-functionalized metallacycles and metallacages and systematically investigated their properties and functions ${ }^{[28]}$. It should be noted that, due to the unique molecular structure of diarylethenes, they could be employed as the backbone for the formation of SCCs or just attached to the periphery of them. In addition, because of the simple coordination mode of $\mathrm{Pd}$ or Pt as well as the research maturity of Pd- or Pt-based SCCs, Pd and Pt have been the most common metals for the construction of diarylethene-based metallacycles and metallacages. This review focuses on the preparation, photophysical and photochemical properties and applications of diarylethene-based metallacycles and metallacages. For clarity, we separate this review into diarylethene-based metallacycles and diarylethene-based metallacages. 


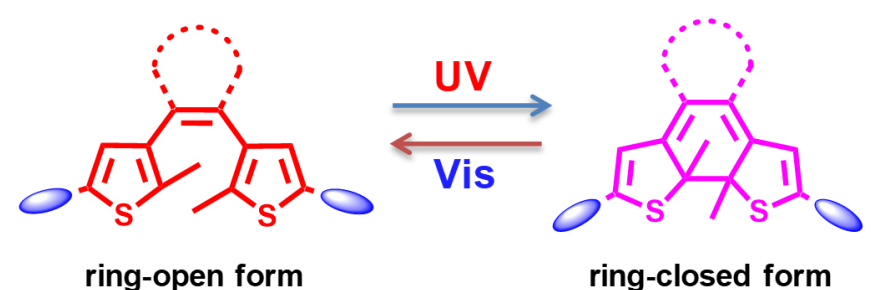

Scheme 1. The reversible structural transformation of diarylethene under irradiation.

\section{DIARYLETHENE-BASED METALLACYCLES}

\section{Diarylethene as the backbone of metallacycles}

In 2001, Murguly et al. ${ }^{[29]}$ reported the synthesis of the early example of diarylethene-based metallacycles and investigated their chiroptical behavior for nondestructive data processing. As shown in Figure 1, treatment of the chiral oxazoline-modified diarylethene ligand 1 or 2 with an equimolar amount of CuOTf $\cdot 0.5 \mathrm{C}_{6} \mathrm{H}_{6}$ provided the rectangular $[2+2]$ metallacycle $\mathrm{Cu}_{2}(\mathbf{1 0})_{2}$ or $\mathrm{Cu}_{2}(2 \mathbf{2})_{2}$, respectively. The metallacycles were well characterized by mass spectra and X-ray crystallography analysis. It was found that the metallacycle $\mathrm{Cu}_{2}(\mathbf{1 0})_{2}$ was a stereochemically pure specie, which was ascribed to the remote chiral induction of the oxazoline moieties and steric hindrance in the metallacycle. The ring-open form metallacycle with stereochemical purity could orientate the two methyl groups on the thiophene ring, thus leading to the ring-closed form metallacycle with stereochemical purity under UV irradiation. ${ }^{1} \mathrm{H} N M R$ experiments showed that the photoconversion yield was about $90 \%$ in the photostationary state, and it could be completely recovered under visible light irradiation. It should be noted that the photoconversion yield and diastereo-selectivity during the photochromic process was affected by the concentration of the ligands. A higher concentration $\left(10^{-3} \mathrm{~mol} / \mathrm{L}\right)$ resulted in a high photoconversion yield and diastereo-selectivity, probably due to the disassembly of the metallacycles at low concentrations. Furthermore, optical rotary dispersion spectra during the photochromic process were performed, which indicated that the ring-open and ring-closed forms of the metallacycle $\mathrm{Cu}_{2}(\mathbf{1 0})_{2}$ exhibited several different spectral regions (e.g., 450 and $475 \mathrm{~nm}$ ) in rotation. In addition, the modulated optical rotation showed good fatigue-resistant property, thus providing possibility for nondestructive data processing.

Light-triggered reversibly structural transformations play an important role in the construction of smart artificial machines. In 2012, Chen et al. ${ }^{[30]}$ reported the synthesis of Pt-based diarylethene hexagons for the first time and studied their photochromic behaviors. As shown in Figure 2, through the treatment of the diarylethene-containing $120^{\circ}$ donor 3 with the classical $120^{\circ} \mathrm{Pt}$ acceptor 4 or $180^{\circ} \mathrm{Pt}$ acceptor 5 , the $[3+3]$ hexagon 6 or [6+6] hexagon 7 was readily obtained through coordination-driven self-assembly. The hexagons were well characterized with ${ }^{1} \mathrm{H}$ NMR spectra, ${ }^{31} \mathrm{P}$ NMR spectra and ESI-TOF-MS. Furthermore, the photochromic property of the hexagons was investigated. As for 6, under $365 \mathrm{~nm}$ irradiation, a new absorption band appeared at $628 \mathrm{~nm}$ accompanied by an obvious color change from colorless to dark cyan, which was caused by the formation of ring-closed form diarylethene. The fluorescence of hexagon 6 was also decreased dramatically under $365 \mathrm{~nm}$ irradiation. Moreover, the absorption and fluorescence of 6 could be completely recovered under visible light irradiation, which could be repeated for 10 cycles without any obvious degradation, indicating its excellent fatigue-resistant property. In addition, the results of ${ }^{1} \mathrm{H}$ NMR and ${ }^{31} \mathrm{P}$ NMR spectra also demonstrated the photochemical reaction could efficiently occur without disturbing the hexagon's structure. More importantly, the photoconversion yield of hexagons 6 and 7 from the ring-open form to ring-closed form was almost quantitative, while, for ligand 3, it was just $88 \%$. This finding suggests that the formation of coordination bond promoted the photochromic process in this study. Further DFT calculations indicated that the antiparallel conformation of the ligand was closer to $120^{\circ}$, which was more favorable for the formation of hexagons according to the principles of "symmetry 
A

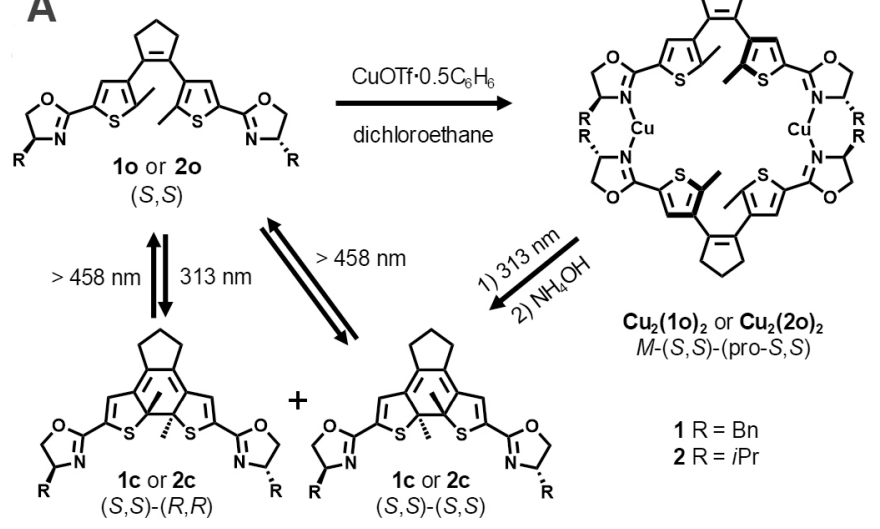

B

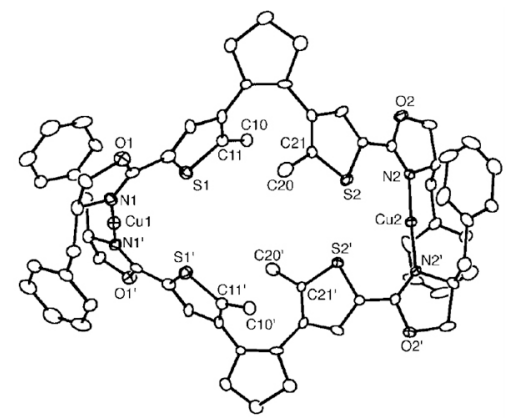

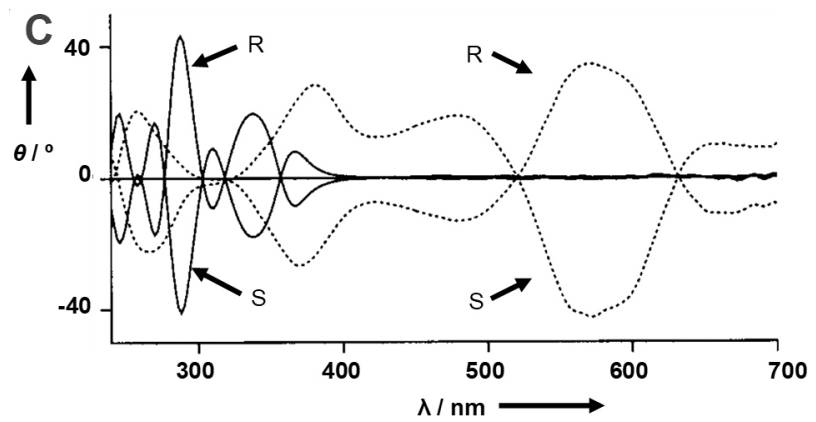

D

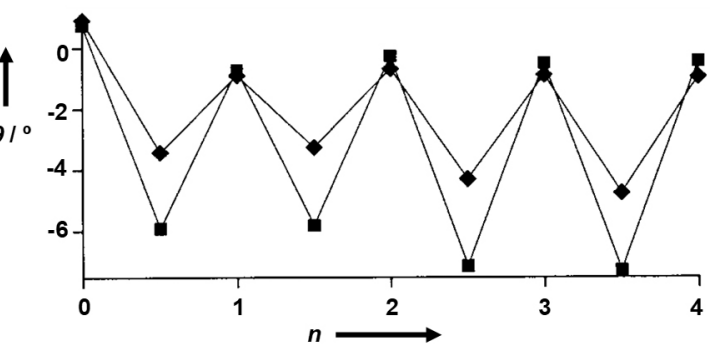

Figure 1. (A) The synthetic route of the metallacycle $\mathrm{Cu}_{2}(10)_{2}$ and $\mathrm{Cu}_{2}(2 \mathrm{o})_{2}$. (B) Crystal structure of $(\mathrm{S}, \mathrm{S})-\mathrm{Cu}_{2}(10)_{2}$. (C) The optical rotary dispersion spectra of 10 with $\mathrm{CuOTf} \cdot 0.5 \mathrm{C}_{6} \mathrm{H}_{6}(-)$ and $1 \mathrm{c}$ with CuOTf $0.5 \mathrm{C}_{6} \mathrm{H}_{6}(\cdots)$. (D) The fatigue-resistant property of the optical rotation of 10 with CuOTf.0.5 $\mathrm{C}_{6} \mathrm{H}_{6}$ at $450 \mathrm{~nm}(\bullet)$ and $475 \mathrm{~nm}(\mathbf{a})$ through altering UV and visible irradiation. This figure is used with permission from Murguly et al. ${ }^{[29]}$. $^{6}$.

interaction" and "directional bonding" ${ }^{[31]}$. In addition, the hexagons with ligands in antiparallel conformation showed a lower energy $(7.67 \mathrm{kcal} / \mathrm{mol})$ than the parallel ones, thus demonstrating their good stability. This research realized the increased photoconversion yield through coordination induction, which laid foundation for the design and construction of new photochromic SCCs.

In 2019, Li et al. ${ }^{[32]}$ reported the conformation-dependent self-assembled behaviors of diarylethenes. The diarylethene-containing ligand $\mathbf{8}$ has two conformations, antiparallel (80) and parallel ( $p$-8), and only the antiparallel conformation 80 is photoactive [Figure 3]. Due to the steric hindrance of the bulky bisbenzo(thiadiazole) group, the two conformations of the ligand could be readily separated by silica-gel chromatography. X-ray crystal indicated that the parallel conformation $p$-8 adopted a $65^{\circ}$ bend angle and the antiparallel 80 showed $155^{\circ}$ bend angle. Further self-assembly experiments manifested that $p-8$ could form [2+2] rhombus 9 or [3+3] triangle 10 with $120^{\circ}$ or $180^{\circ}$ di-platinum acceptors, respectively, while [3+3] and $[6+6]$ hexagons (11 and 12) were obtained for $\mathbf{8 0}$, which was in agreement with the principles of "symmetry interaction" and "directional bonding". By mixing $p-8$ and 80 together with $180^{\circ}$ di-platinum acceptors, [3+3] triangles and [6+6] hexagons (10 and 12) were formed individually, conforming their selfsorting behavior. Furthermore, NMR spectra and UV-Vis and fluorescence spectra were conducted to study their photochromic property. The results indicate that the metallacycles with parallel conformation showed no photochromism and the antiparallel ones exhibited excellent photochromic property such as high photocyclization quantum yield (66.8\% and $61.2 \%$ for 11 and 12, respectively) and good fatigue-resistant property. In addition, the cycloreversion quantum yields for the ring-closed metallacycles of 11 and 12 was 


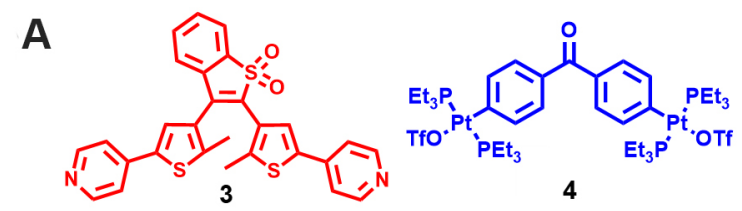

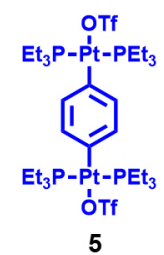

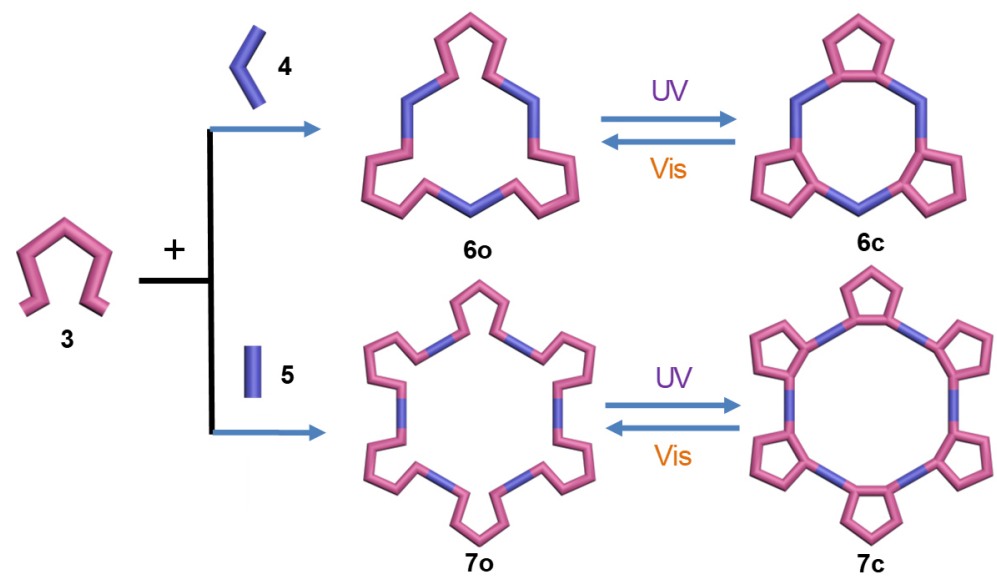

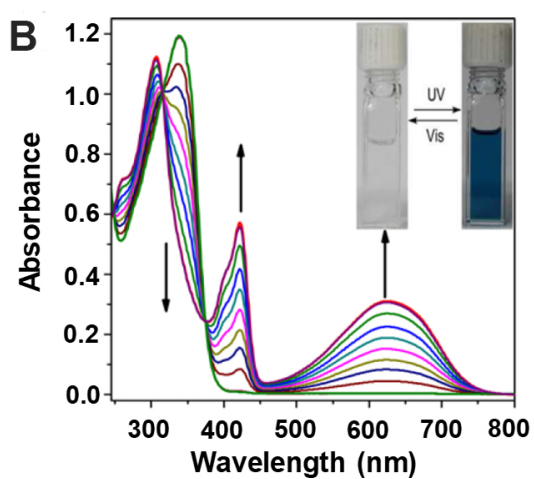

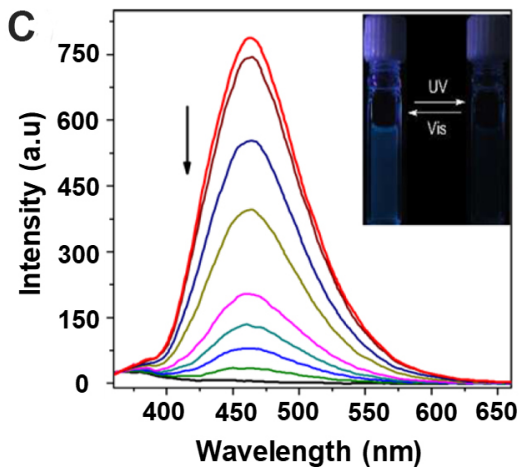

Figure 2. (A) The synthesis of the multi-bisthienylethene hexagons 6 and $\mathbf{7}$ and their structural transformations. Absorption (B) and emission (C) spectral changes of hexagon 60 upon irradiation at $365 \mathrm{~nm}$. This figure is used with permission from Chen et al. ${ }^{[30]}$.

$6.3 \%$ and $6.5 \%$, respectively. Such a conformation-dependent self-assembled and photochromic behaviors of diarylethene-based metallacycles could be applied in developing smart materials for catalysis and precise drug delivery.

Furthermore, in 2019, the two chiral conformers (P and M) of $\mathbf{8 0}$ were successfully separated. Similar to the racemate, the chiral diarylethene ligands could also assembly with $120^{\circ}$ di-platinum acceptor to form [3+3] metallacycles P-110 or M-11o [Figure 4] ${ }^{[33]}$. The metallacycles exhibited obvious CD signals similar to the ligands. Under UV irradiation, new signals appeared in the CD spectra, which were ascribed to the formation of ring-closed diarylethene. The CD signals could be repeated for 12 cycles without degradation, thus confirming the photo-controlled chirality switching within the metallacycles. In addition, the combined results from ${ }^{1} \mathrm{H}$ NMR, ${ }^{13} \mathrm{C}$ NMR, ${ }^{31} \mathrm{P}$ NMR and HPLC separation indicate the photochromic process of the three diarylethene subunits within the metallacycle was a conversion process rather than a step-by-step conversion. Furthermore, the metallacycle was doped into poly(D/L-lactic acid) to form a film. By taking advantage of the excellent photoreversibility of the optical rotation at $633 \mathrm{~nm}$, non-destructive "writing", "erasing" and "reading" were realized within the film, which showed potential applications in information encoding.

As for the construction of photoresponsive chirality-tunable metallacycles, except for the self-assembly of chiral diarylethene ligands with metal, integration of achiral diarylethene with chiral building blocks into one metallacycle is another choice. In 2018, a series of metallacycles containing both photochromic diarylethene subunits and chiral 1,1'-bi-2-naphthol (BINOL) subunits was prepared by Yang via coordination-driven self-assembly and their photoresponsive chirality-tunable property was investigated ${ }^{[34]}$. As shown in Figure 5, by mixing two ligands, $(S)-13$ and 14 or 15 , in acetone/ $\mathrm{H}_{2} \mathrm{O}$ at $55{ }^{\circ} \mathrm{C}$ for $8 \mathrm{~h}$ and 

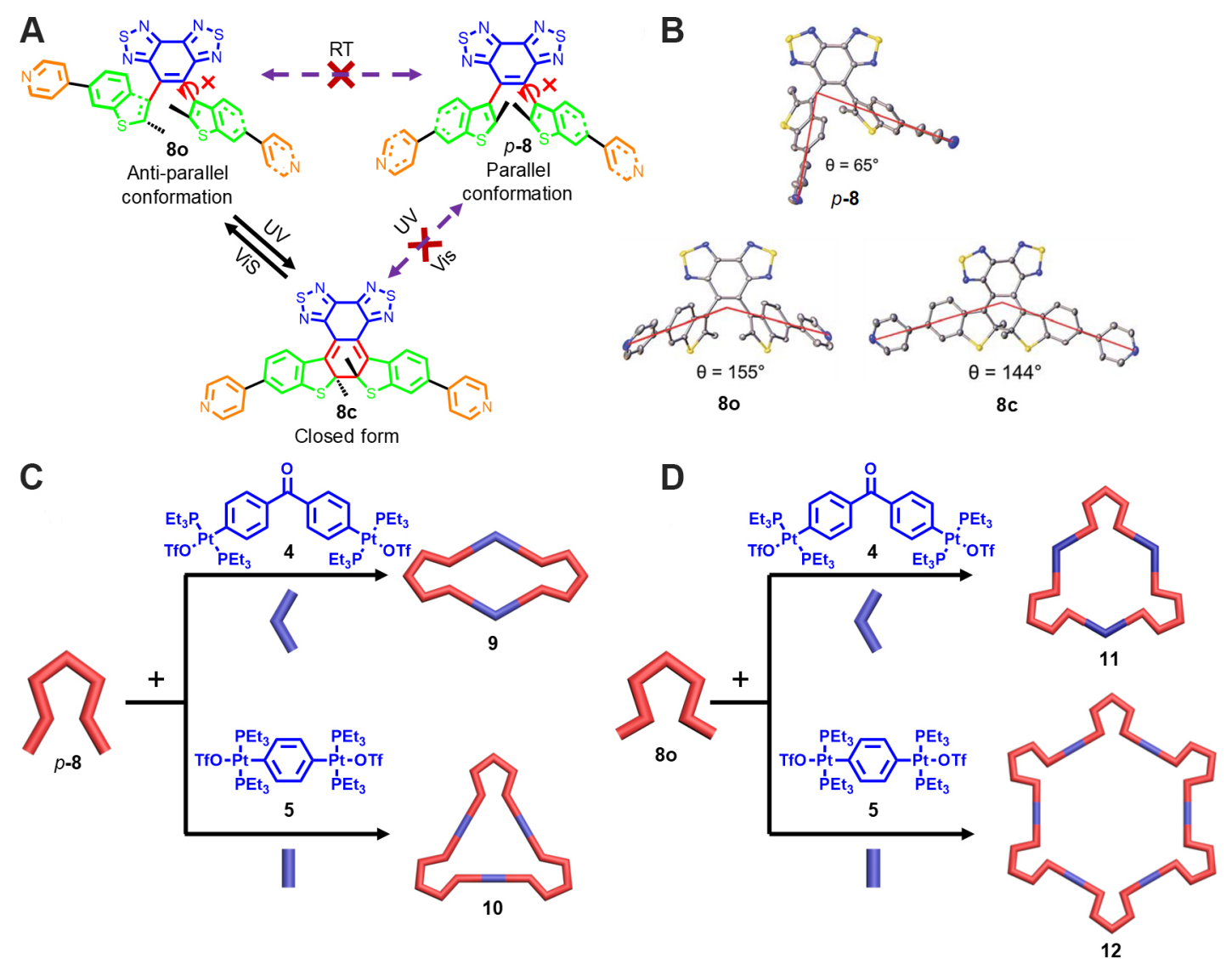

Figure 3. (A) The conversion relationship between the different diarylethene isomers. (B) Crystal structures of $p-8,80$ and $8 \mathrm{c}$. (C) The preparation of the metallacages $\mathbf{9}$ and $\mathbf{1 0}$ from $p$-8. (D) The preparation of the metallacages $\mathbf{1 1}$ and $\mathbf{1 2}$ from $\mathbf{8 0}$. This figure is used with permission from Li et al. ${ }^{[32]}$.

subsequent anion change with $\mathrm{KPF}_{6}$, two [2+2] rhombus $(S)-\mathbf{1 6 0}$ and $(S)-\mathbf{1 7 0}$ were readily obtained. The metallacycles were well characterized with NMR spectra and ESI-TOF-MS. The photochromic studies from UV and NMR spectra indicated the metallacycles showed obvious photochromism and moderate fatigueresistant property. Interestingly, under irradiation at $365 \mathrm{~nm}$, an increase in the intensity of CD signals at 240 and $360 \mathrm{~nm}$ for the metallacycle (S)-170 was observed, which was probably due to the dihedral angle changes of BONIL units induced by geometrical structure transformation of diarylethene units during photochromism. Moreover, the photoresponsive chirality regulation was fully reversible under UV and visible light irradiation, which might be useful for the construction of photoresponsive supramolecular systems for asymmetric catalysis and chiral recognition.

It should be noted that, even though the above-mentioned diarylethene-based metallacycles exhibited excellent photophysical properties and ingratiating applications, they showed no fluorescence or weak fluorescence whether in the ring-open form or ring-closed form. The possible reason might be the competition between photochromic process and luminescence process, which thus hampered their further applications. In 2019, Qin et al. ${ }^{[35]}$ reported the construction of a series of diarylethene-based metallacycles with brilliant fluorescence through in situ light irradiation. As shown in Figure 6, treating the diarylethene ligands $\mathbf{1 8 0}$ and $\mathbf{1 9 0}$ bearing the 1,2-bis(2-ethyl-6-iodo-1-benzothiophen-1,1-dioxide-3-yl) perfluorocyclopentene group with $120^{\circ}$ di-platinum acceptor afforded the two [3+3] hexagons 200 and $\mathbf{2 1 0}$, respectively, almost quantitatively. The metallacycles were well characterized with NMR spectra and ESI- 


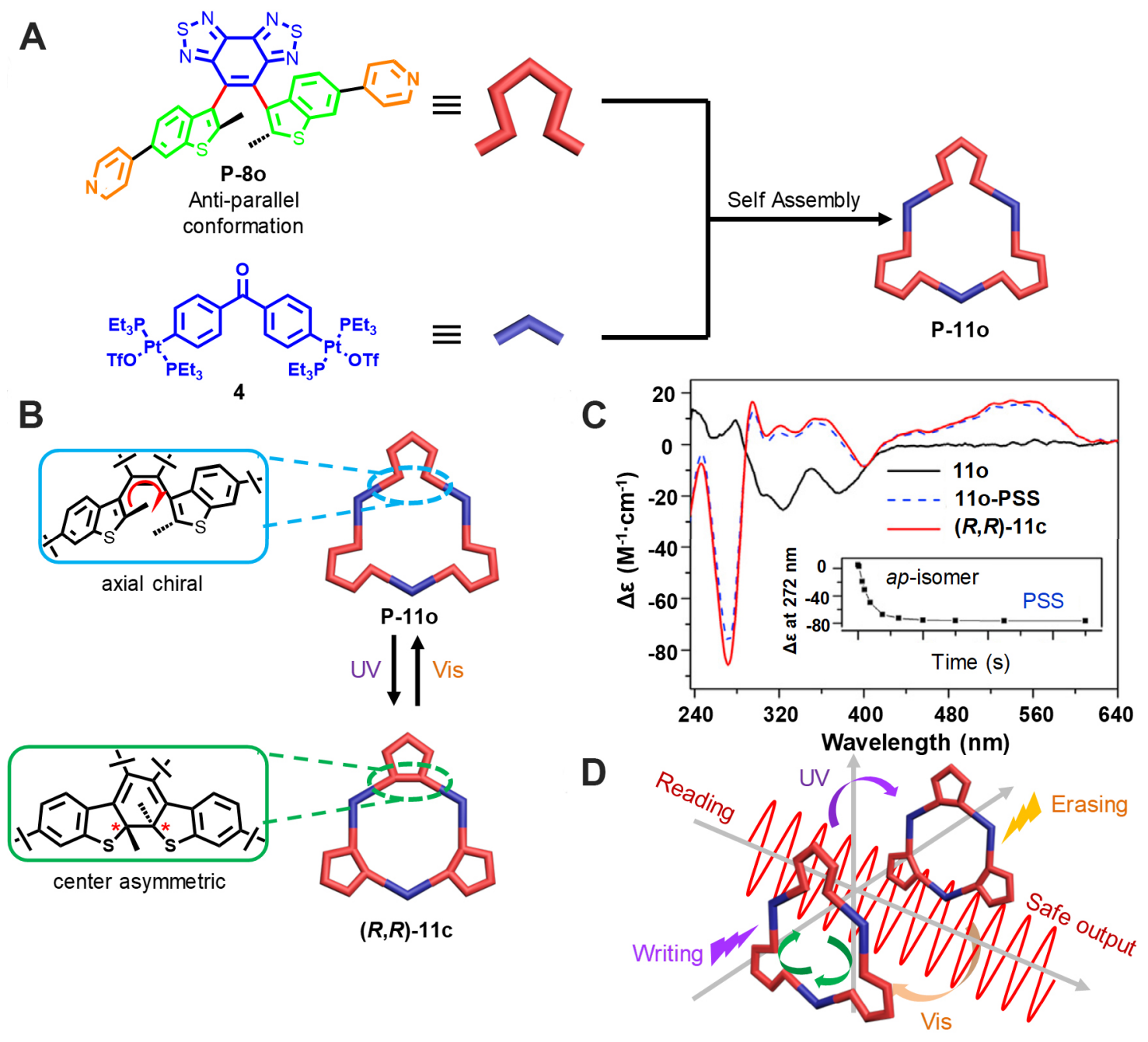

Figure 4. (A) Graphical representation of the construction of chiral metallacage P-11o form the chiral diarylethene ligand P-80. (B) Photoisomerization between the two isomers P-11o and $(R, R)-11 \mathrm{c}$. (C) The CD spectral changes of P-11o under UV irradiation. (D) Schematic illustration of the non-destructive "writing", "erasing" and "reading" with chiral metallacycles. This figure is used with permission from Li et al. ${ }^{[33]}$.

TOF-MS. DFT calculations indicated that the antiparallel configurations of the ligands were close to $120^{\circ}$, thus resulting in the facile construction of [3+3] hexagons. Under UV irradiation, the color of the solution for metallacycle $\mathbf{2 0 0}$ or $\mathbf{2 1 0}$ changed from colorless to yellow or red, respectively, accompanied by the appearance of a new absorption peak at 460 or $505 \mathrm{~nm}$, respectively. More importantly, the metallacycles initially showed no fluorescence in solution but exhibited bright yellow or orange fluorescence under UV irradiation for $\mathbf{2 0 0}$ or $\mathbf{2 1 0}$, respectively, which is different from most previous photochromic systems. Moreover, the ring-closed form metallacycles displayed relatively high quantum yields $\left(\Phi_{\mathrm{F}}=0.5\right)$, and the fluorescence wavelength and lifetime of the metallacycles were almost not affected by metal coordination. This study realized in situ construction of high-emissive metallacycles under irradiation, which could be helpful in developing supramolecular materials for super-resolution fluorescence imaging.

\section{Diarylethene attached to the periphery of metallacycles}

Another way to construct diarylethene-based metallacycles is to attach the diarylethene units onto the periphery of metallacycles. In recent years, photoswitchable fluorescent systems have gained increasing 

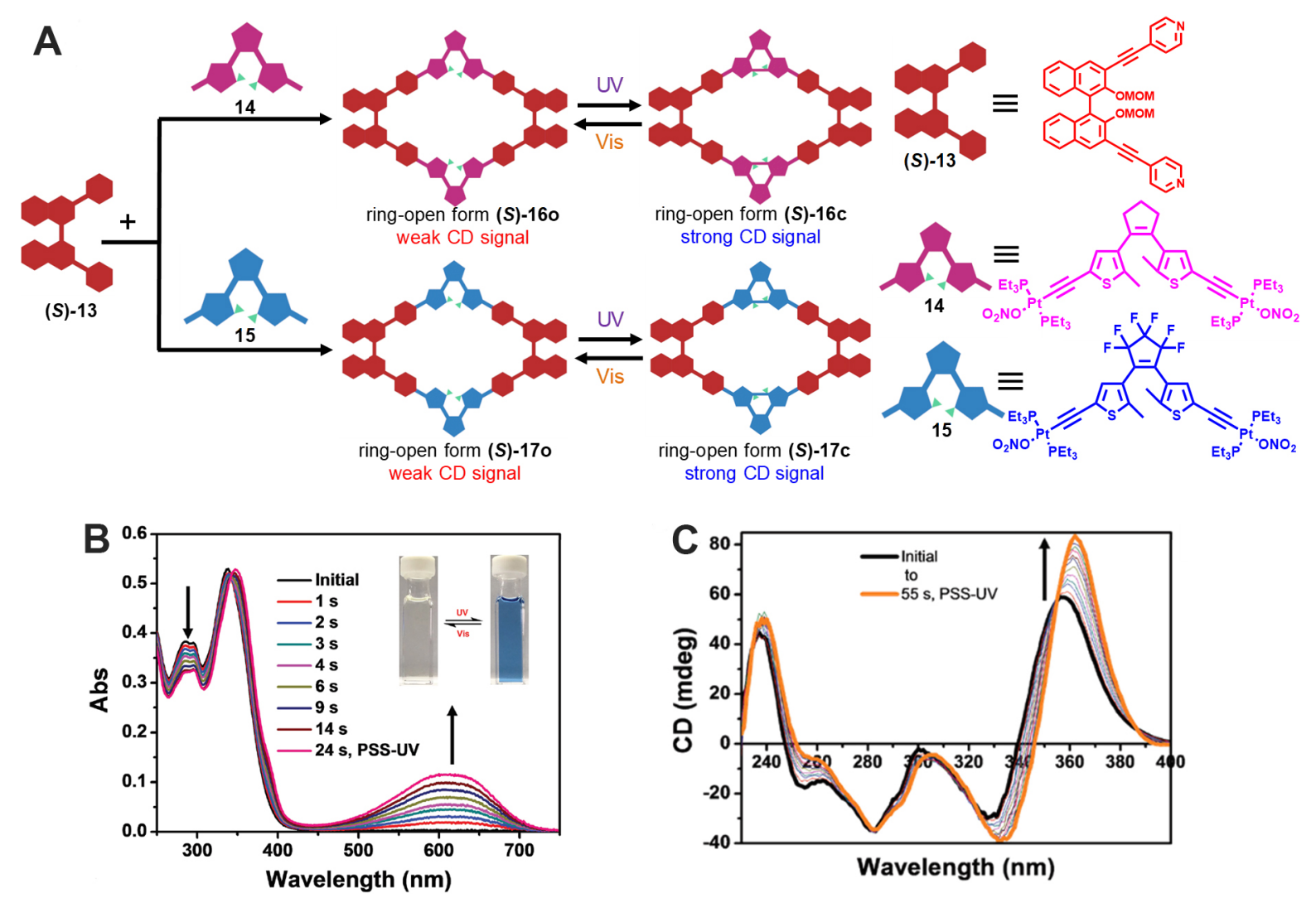

Figure 5. (A) Graphical representation of the synthesis of metallacages (S)-160 and (S)-17o and their structural transformations. (B) Absorption spectral changes of metallacycle (S)-17o under $365 \mathrm{~nm}$ irradiation. (C) CD spectral changes of metallacycle (S)-17o under $365 \mathrm{~nm}$ irradiation. This figure is used with permission from Wang et al. ${ }^{[34]}$.

attention due to their applications in super-resolution imaging, anti-counterfeiting and information storage. Qin et al. ${ }^{[36]}$ reported the synthesis of a heterometallic Ir-Pt macrocycle with photoswitchable luminescence behavior in 2019. Through treatment of the Ir complex-containing $60^{\circ}$ dipyridinyl donor 22 and the diarylethene-containing $120^{\circ}$ di-platinum acceptor 230 at $55{ }^{\circ} \mathrm{C}$, the [2+2] rhombus 240 was readily obtained [Figure 7]. Under irradiation at $365 \mathrm{~nm}$, a new absorption band at $560 \mathrm{~nm}$ appeared, accompanied by an obvious color change of the solution from light-yellow to purple due to the formation of ring-closed form diarylethene. Moreover, the fluorescence of the metallacycle $\mathbf{2 4 0}$ was dramatically declined, which was ascribed to the intramolecular Förster resonance energy transfer (FRET) between the Ir complex and ringclosed form diarylethene. In addition, the absorption and fluorescence of the metallacycle could be recovered under visible light irradiation and the metallacycle showed good fatigue-resistant property. DFT calculation indicated that the distance between the two building blocks was about $3.0 \mathrm{~nm}$ and the energy level was suitable, thus demonstrating the efficient photoswitchable FRET behavior within the metallacycle. Furthermore, visual experiments of the metallacycle $\mathbf{2 4 0}$ were conducted and the metallacycle exhibited obvious light-controlled luminescence switching both on filter paper and poly (vinylidene fluoride) film, which showed potential applications in photoswitchable molecular devices and information storage.

Controllable generation of singlet oxygen $\left({ }^{1} \mathrm{O}_{2}\right)$ plays an important role in decreasing the side effects to normal tissues during photodynamic therapy. In 2019, a dual-stage metallacycle containing both porphyrin photosensitizer and diarylethene photochromic switch was reported by Yang's group, which featured interesting light-controlled generation of ${ }^{1} \mathrm{O}_{2}^{[37]}$. As shown in Figure 8, the [3+3] hexagon 260 was prepared 


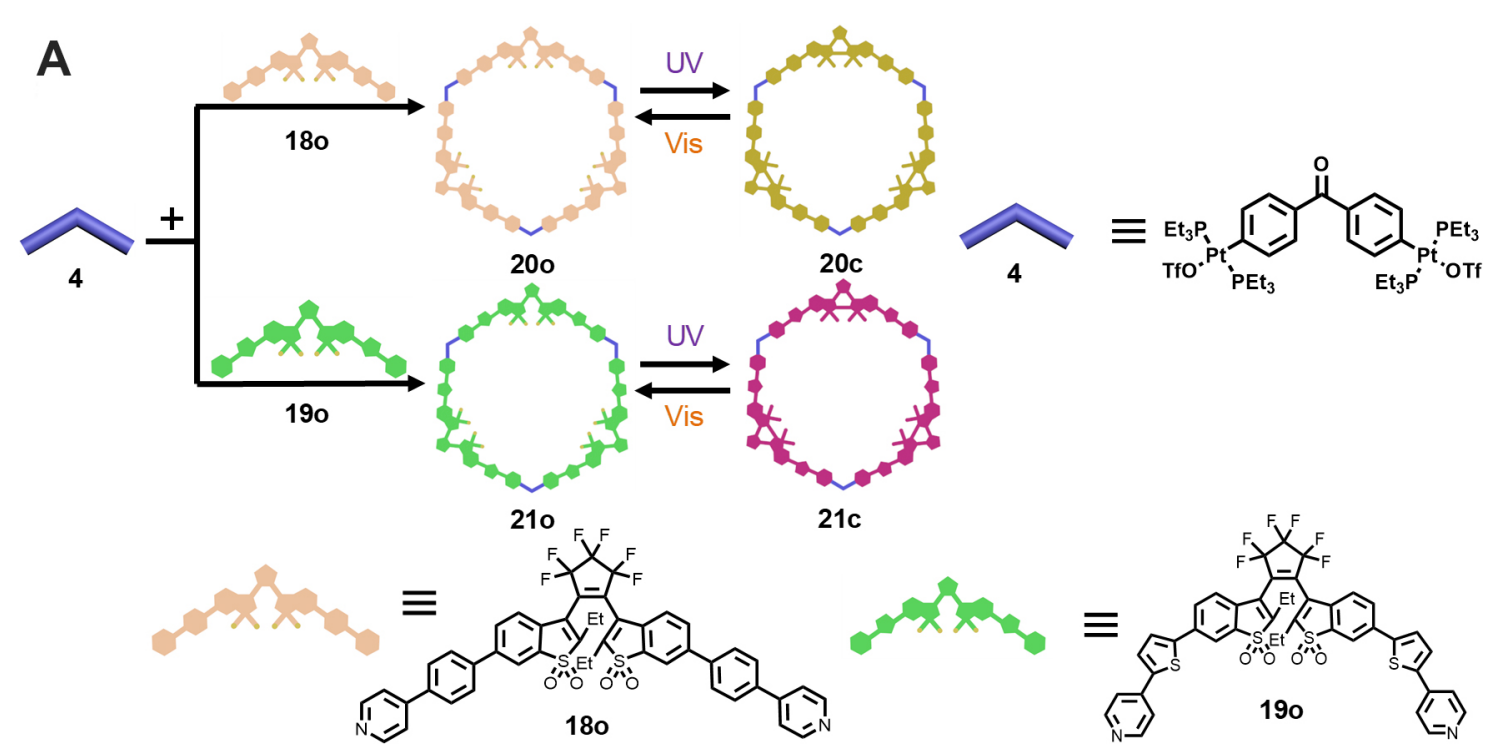

B
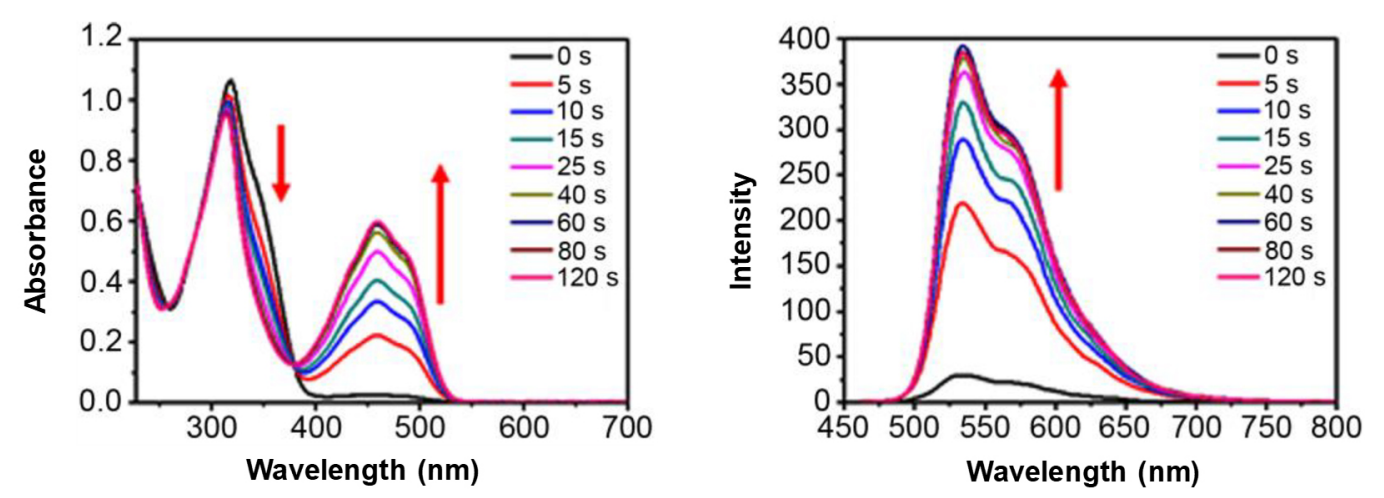

Figure 6. (A) Graphical representation of the self-assembled metallacycles 200 and 210 from the diarylethene ligands 180 and 190 and their structural transformations. (B) Absorption and fluorescent spectral changes of metallacycle 200 under $365 \mathrm{~nm}$ irradiation. This figure is used with permission from Qin et al. ${ }^{[35]}$.

by mixing a porphyrin-functionalized $120^{\circ}$ dipyridinyl donor 25 and the diarylethene-containing $120^{\circ}$ diplatinum acceptor $\mathbf{2 3 0}$ via coordination-driven self-assembly. The combined results from NMR spectra and absorption and fluorescence spectra manifest that the metallacycle 260 possessed excellent photochromic property and good fatigue-resistant property. Furthermore, the ${ }^{1} \mathrm{O}_{2}$ generation ability of the metallacycle at different state was investigated by using singlet oxygen sensor green (SOSG) as the probe. It was found that the ring-open form metallacycle $\mathbf{2 6 0}$ showed efficient ${ }^{1} \mathrm{O}_{2}$ generation, whereas the ring-closed form metallacycle $26 \mathrm{c}$ showed almost no ${ }^{1} \mathrm{O}_{2}$ generation. The results from theoretical calculations reveal that such a behavior of controllable generation of ${ }^{1} \mathrm{O}_{2}$ was ascribed to the photoswitchable energy transfer from porphyrin to diarylethene photoswitch. Furthermore, to explore the possibility of the applications in biological systems, the metallacycles $\mathbf{2 6 0}$ and $\mathbf{2 6 c}$ were encapsulated into an amphiphilic polymer mPEGDSPE, leading to the formation of nanoparticles. The experimental results indicate that O-NPs (the ringopen form of nanoparticles) showed a higher ${ }^{1} \mathrm{O}_{2}$ generation ability than C-NPs (the ring-closed form of nanoparticles). Further in vitro and in vivo experiments both indicated that O-NPs showed stronger antitumor effects under irradiation than C-NPs because of the higher ${ }^{1} \mathrm{O}_{2}$ generation ability of O-NPs. Thus, light-controlled generation of singlet oxygen was achieved in the discrete supramolecular coordination complexes, which provided a blueprint for the development of SCCs for biological applications. 
A
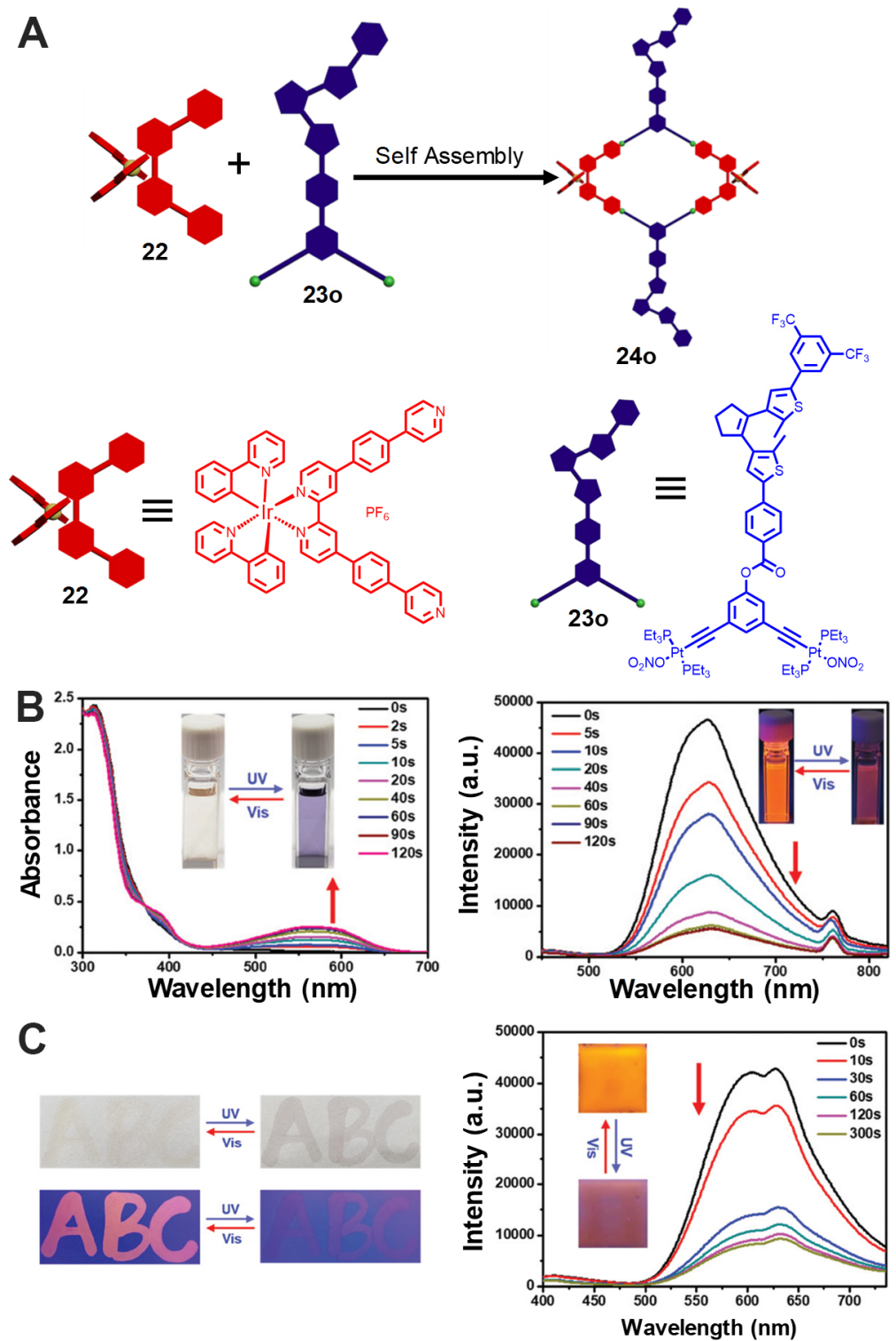

Figure 7. (A) Synthetic route of the dual-functional metallacycle $\mathbf{2 4 0}$ from 22 and $\mathbf{2 3 0}$. (B) Absorption and emission spectral changes of metallacycle 240 under $365 \mathrm{~nm}$ irradiation. (C) Light-controlled luminescence switching on a filter paper and in the poly (vinylidene fluoride) film. This figure is used with permission from Qin et al. ${ }^{[36]}$.

\section{DIARYLETHENE-BASED METALLACAGES}

\section{Diarylethene-based metallacages via Pd-ligand coordination}

Han et al. ${ }^{[38]}$ made significant contributions in the field of diarylethene-based metallacages. In 2013, they reported the preparation of a diarylethene-based metallacage for the first time, which exhibited lightinduced guest uptake/release behavior. By reaction of the diarylethene-containing dipyridinyl ligand $\mathbf{2 7 0}$ and $\left[\mathrm{Pd}\left(\mathrm{CH}_{3} \mathrm{CN}\right)_{4}\right]\left(\mathrm{BF}_{4}\right)_{2}$ in a 2:1 ratio in $\mathrm{CD}_{3} \mathrm{CN}$, the $\mathrm{M}_{2} \mathrm{~L}_{4}$-type metallacage 280 was formed quantitatively [Figure 9]. The metallacage was well characterized with 1D and 2D NMR spectra and MS spectra. X-ray crystal structure revealed that the two $\left\{\mathrm{Pd}(\text { pyridine })_{4}\right\}$ planes were not eventually congruent but led to the congruent shape of the metallacage, which might be due to the flexible conformation of diarylethene moiety. In addition, the metallacage $\mathbf{2 8 0}$ showed excellent photochromic property by monitoring the changes of NMR spectra and absorption spectra. The results of $2 \mathrm{D}$ diffusion-ordered spectroscopy (DOSY) 
A

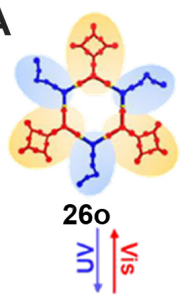

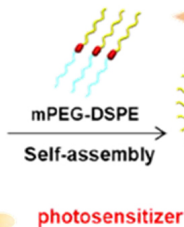

photoswitch

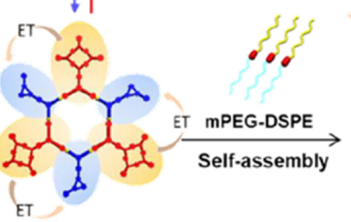

26c

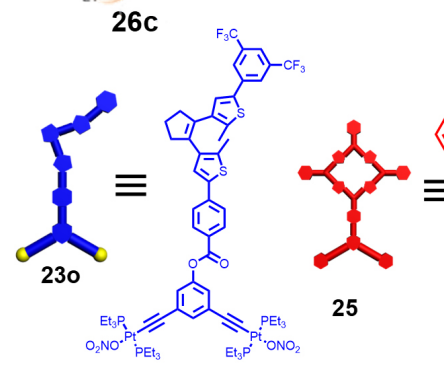

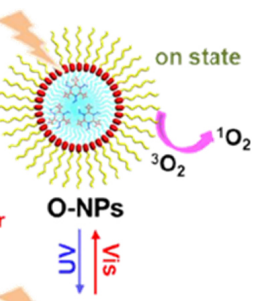

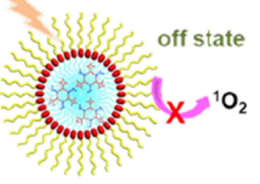

C-NPs
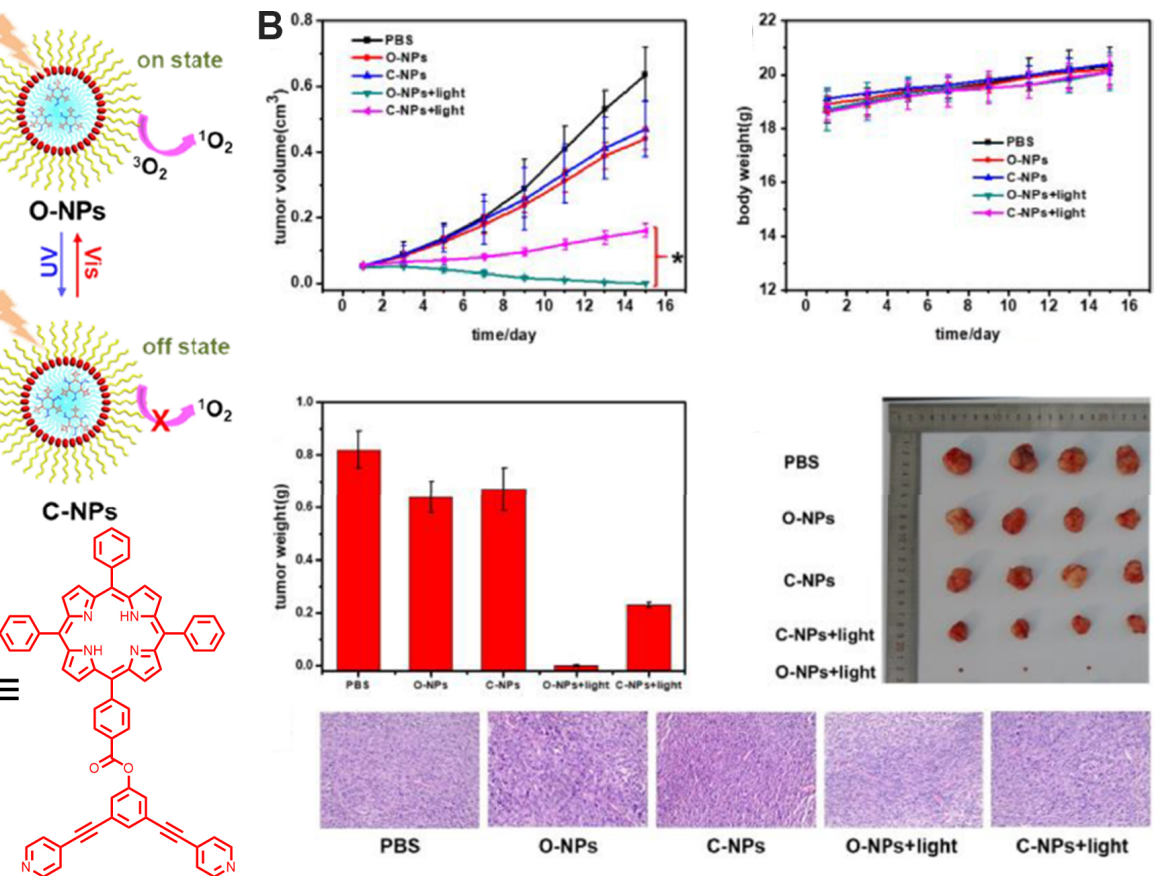

O-NPs

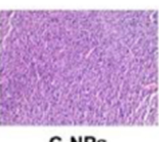

C-NPs

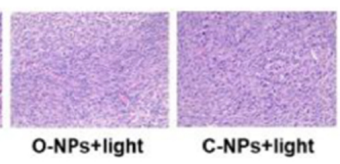

Figure 8. (A) Graphical representation of the light-controlled generation of ${ }^{1} \mathrm{O}_{2}$ within the metallacycle 26 and the nanoparticles. (B) In vivo photodynamic therapy efficacy on HeLa tumor-bearing mice of the nanoparticles. This figure is used with permission from Qin et al. ${ }^{[37]}$.
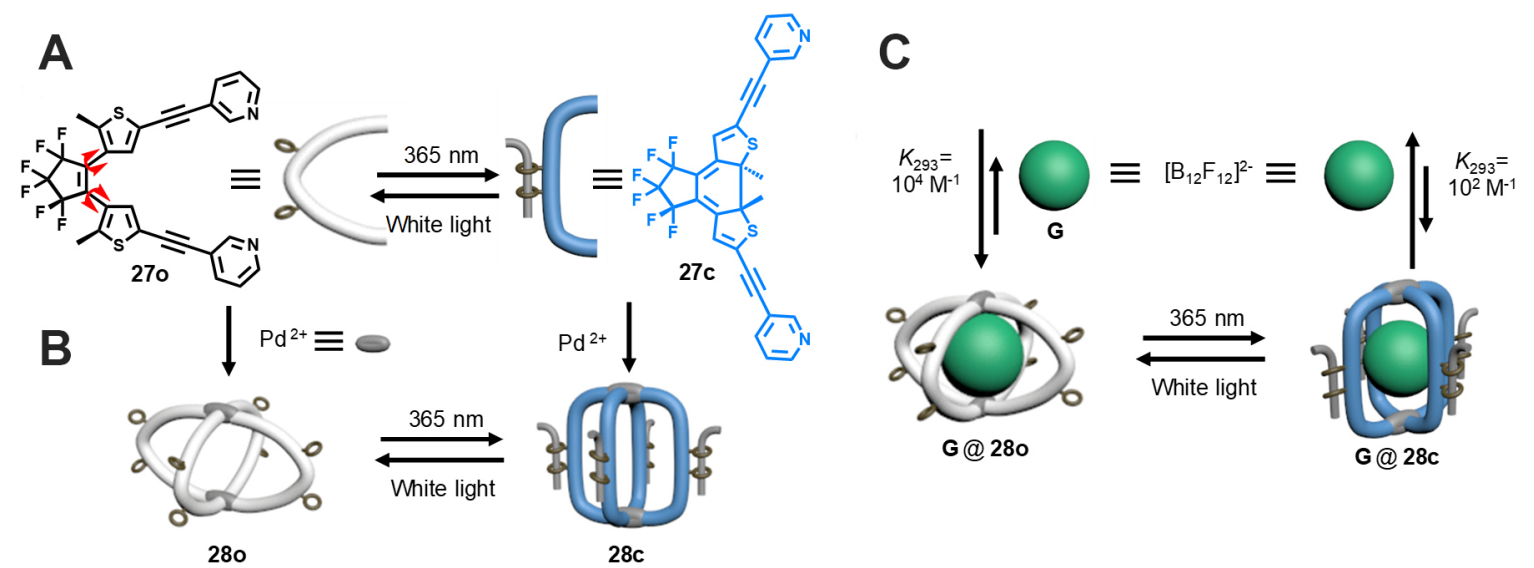

Figure 9. Photoisomerization of (A) the diarylethene ligand $\mathbf{2 7}$ and (B) the metallacage $\mathbf{2 8}$. (C) Cage $\mathbf{2 8 0}$ shows a much stronger affinity for $\mathrm{G}\left(\mathrm{G}=\left[\mathrm{B}_{12} \mathrm{~F}_{12}\right]^{2-}\right)$ than cage $28 \mathrm{c}$.

NMR measurements indicate that the ring-open form and ring-closed form metallacages had different cavity sizes, 7.04 and $8.67 \AA$ for $\mathbf{2 8 0}$ and $\mathbf{2 8 c}$, respectively. The relatively smaller size of the ring-open form metallacage was probably due to the conformational flexibility of the ring-open form diarylethene and the rigid structure of the ring-closed form diarylethene. Furthermore, the host/guest behavior of the metallacage was investigated. It was demonstrated that dodecafluorododecaborate anion $\left(\left[\mathrm{B}_{12} \mathrm{~F}_{12}\right]^{2-}\right)$ could be efficiently encapsulated in the cage with bonding constants of $K_{293}=3.2 \times 10^{4} \mathrm{M}^{-1}$ and $K_{293}=6.7 \times 10^{2} \mathrm{M}^{-1}$ for 280 and $\mathbf{2 8 c}$, respectively. The stronger affinity of $\mathbf{2 8 0}$ for the guest was probably due to the conformational flexibility of ring-open form diarylethene, which exhibited an induction-fit effect, while the rigid structure of $\mathbf{2 8 c}$ was not able to adjust its cavity to match the guest. By taking advantage of the light-triggered 
structural transformation of the metallacage, photoinduced guest uptake/release was realized.

Furthermore, in 2016, Han et al. ${ }^{[39]}$ reported light-controlled structural conversion between a self-assembled triangle and a rhombicuboctahedral sphere within diarylethene-based SCCs. As shown in Figure 10, by heating a mixture of the diarylethene-based dipyridinyl ligand $\mathbf{2 9 0}$ at the para-position with $\left[\mathrm{Pd}\left(\mathrm{CH}_{3} \mathrm{CN}\right)_{4}\right]\left(\mathrm{BF}_{4}\right)_{2}$ in a $2: 1$ ratio in $\mathrm{CD}_{3} \mathrm{CN}$ at $70{ }^{\circ} \mathrm{C}$, the $\mathrm{M}_{3} \mathrm{~L}_{6}$ three-membered-ring product 30 with a small amount of $\mathrm{M}_{4} \mathrm{~L}_{8}$ four-membered-ring product was obtained, as confirmed with $1 \mathrm{D}$ and $2 \mathrm{D}$ NMR spectra and MS spectra. Under UV irradiation, the mixture of the triangle and square converted into a new specie with broad NMR spectra signals, which was confirmed to be $\mathrm{M}_{24} \mathrm{~L}_{48}$ type rhombicuboctahedron 32c by CSI-MS spectra. The results from transmission electron microscopy (TEM), atomic force microscopy and grazing-incidence small-angle X-ray scattering (GISAXS) experiments indicate that this large metallacage $32 \mathrm{c}$ showed a diameter of about 6-7 nm, which was consistent with the result from 2D DOSY spectra $(7.0 \mathrm{~nm})$. Furthermore, the photoreaction dynamics of the metallacage was studied, which revealed that a very long time $(15 \mathrm{~h})$ was needed for the complete structural conversion from 30 to $32 \mathrm{c}$. The possible reason is that the diarylethene units within the ring-open metallacage adopted a photoinactive parallel conformation and the tiny amount of free ligand in the mixture transferred into ring-closed form under irradiation, thus leading to a slow equilibrium shifting. In addition, the reverse conversion of $\mathrm{M}_{24} \mathrm{~L}_{48}$ rhombicuboctahedron into the small $\mathrm{M}_{3} \mathrm{~L}_{6}$ rings was not straightforward and the ring-closed form diarylethene in the rhombicuboctahedron recovered into the ring-open state, followed by the slow disassembly-reassembly into the small $\mathrm{M}_{3} \mathrm{~L}_{6}$ rings. This study realized the light-controlled structural conversion between different self-assembled SCCs, which played an important role in developing SCCbased molecular machines. In addition, some other diarylethene-based metallacages were also constructed by Li et al. ${ }^{[40-42]}$ and exhibited interesting properties and functions.

In 2018, Gu et al. ${ }^{[43]}$ realized light-controlled topology transformation in polymer networks by making use of diarylethene-based metallacages as crosslinks. Firstly, the two terminals of the PEG chains were functionalized with diarylethene-based dipyridinyl ligand to afford the polymer ligand $\mathbf{3 5 0}$ [Figure 11]. By treatment of the 350 with 1.0 eq. $\mathrm{Pd}\left(\mathrm{CH}_{3} \mathrm{CN}\right)_{4}\left(\mathrm{BF}_{4}\right)_{2}$ in $\mathrm{CH}_{3} \mathrm{CN}$, a dark-brown gel (o-gel) with the diarylethene in ring-open form was obtained. Under UV irradiation, the o-gel transformed into a dark-blue gel (c-gel) due to the ring-closure reactions of diarylethenes. It should be noted that discrete diarylethenebased metallacages constituted the crosslinks of the polymer gels. Similar to the polymer ligand $\mathbf{3 5 0}$, the model diarylethene ligand without PEG chain exhibited structural conversion between small $\mathrm{Pd}_{3} \mathrm{~L}_{6}$ triangles and large $\mathrm{Pd}_{24} \mathrm{~L}_{48}$ rhombicuboctahedra under UV and visible light irradiation, respectively, as confirmed by NMR and ESI-TOF-MS spectra. Thus, the structural changes of the crosslinks led to a substantial change of the polymer topology networks of the polymer gel, which played an important role in the physical properties including storage modulus G' and self-healing properties. For example, the c-gel showed 1.7 times higher $\mathrm{G}^{\prime}$ than the o-gel ( 8.3 and $14.1 \mathrm{kPa}$ for o-gel and c-gel, respectively) due to more topological defects in the c-gel. In addition, the results of SAXS and DFT calculations reveal that the c-gel had a higher defect tolerance and less dynamics than o-gel, which was derived from the inherent high branch functionality of the c-gel. Thus, the o-gel exhibited remarkable self-healing properties, while the c-gel showed no self-healing under the same condition. Moreover, the polymer gel showed a moderate fatigueresistant property, as confirmed by the shear modulus, SAXS and molecular calculations. This study successfully prepared a photoresponsive polymer gel by using diarylethene-based metallacages as crosslinks. The resulting o-gel and c-gel showed remarkable difference in storage modulus and self-healing properties due to the photoswitchable topology transformation in polymer networks under light irradiation. 


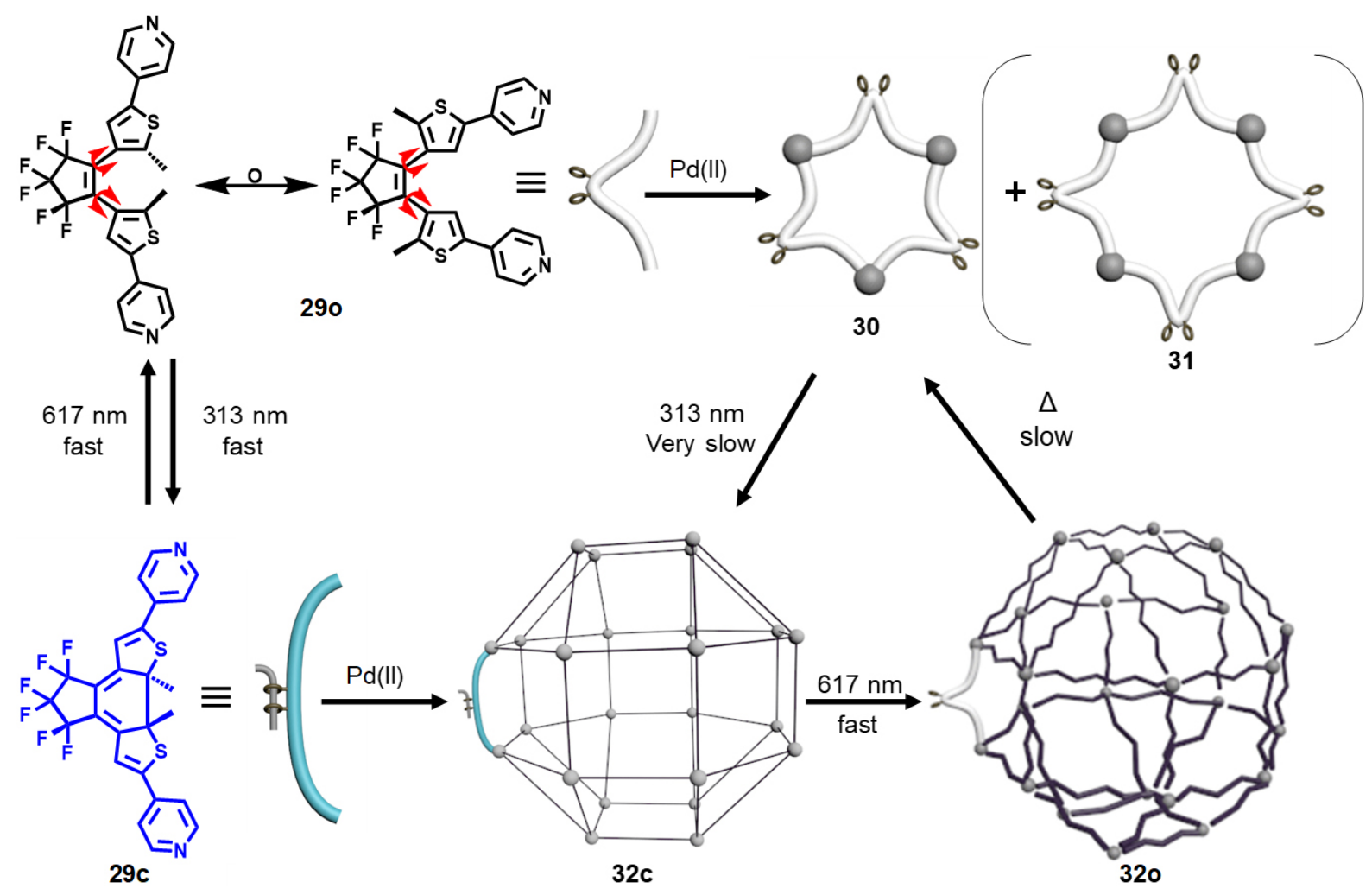

Figure 10. Graphical representation of self-assembly and structural conversion between a self-assembled triangle and a rhombicuboctahedral sphere under light irradiation.

Except for the induction of polymer chain on diarylethene ligand for the construction of photoresponsive gels, the diarylethene-based metallacage itself could also form supramolecular gels under suitable conditions. In 2015, Wei et al. ${ }^{[4]]}$ reported a diarylethene-based $\mathrm{M}_{2} \mathrm{~L}_{4}$ type metallacage with multiresponsivity. The metallacage 37 was similar to the previous reported one (28). Under UV and visible light irradiation, the metallacage 37 showed excellent photochromic property with full reversibility. Interestingly, the ring-open form metallacage 370 exhibited solution-to-gel transformation in common solvents such as DMF and DMSO at room temperature [Figure 12]. Further, the combined results from NMR spectra, SEM, TEM, dynamic light scattering and rheological tests indicate that the formation of gel was affected by temperature, light, coordination anions and shear force, thus endowing the gel with multistimuli-responsive property. The photo-induced solution-to-gel transformation was ascribed to the flexible conformation of the ring-open form diarylethene, which was beneficial for the multiple noncovalent interactions between the metallacage. In addition, the porous metallacage kept intact during the solution/gel transformation, which was helpful in developing new porous materials with multi-stimuli-responsivity.

\section{Diarylethene-based metallacages through coordination with other metals}

In 2019, Li et al. ${ }^{[45]}$ reported the controlled modulation of the magnetic properties within diarylethene-based metallacages. Treatment of the diarylethene ligand $\mathbf{3 8 0}$ with $\mathrm{Fe}(\mathrm{OTf})_{2}$ under room temperature afforded the metallacage $\mathrm{Fe}^{2+}{ }_{2}(\mathbf{3 8 0})_{3}$ [Figure 13]. X-ray crystallography analysis indicated that the diarylethene ligand within $\mathrm{Fe}_{2}{ }_{2}(\mathbf{3 8 0})_{3}$ was in the antiparallel conformation and the metallacage adopted a triple-stranded helical structure with an average Fe-N distance of $1.972 \AA$, suggesting its low-spin (LS) diamagnetic Fe $\mathrm{Fe}^{\mathrm{II}}$ state. Under irradiation at $365 \mathrm{~nm}$, the ring-open form $\mathrm{Fe}_{2}{ }_{2}{ }_{2}(\mathbf{3 8 0})_{3}$ converted into its ring-closed form $\mathrm{Fe}_{2}{ }_{2}(\mathbf{3 8 c})_{3}$. Moreover, DFT calculations indicated that $\mathrm{Fe}^{2+}{ }_{2}(38 \mathrm{c})_{3}$ exhibited a higher energy $(48.5 \mathrm{kcal} / \mathrm{mol})$ in the 
A

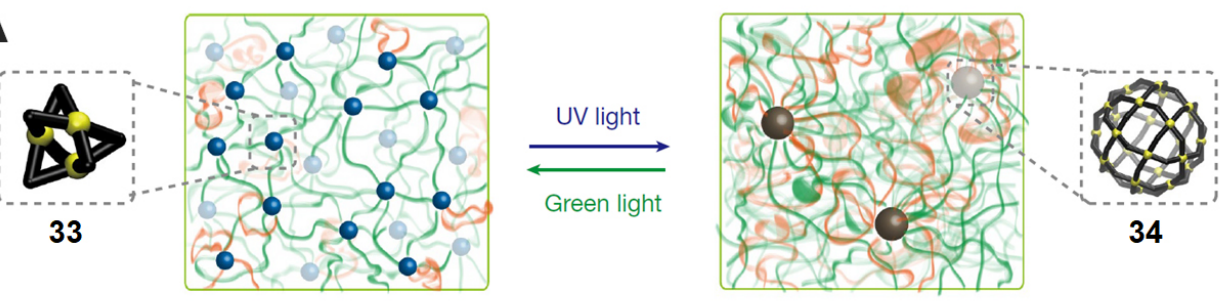

B

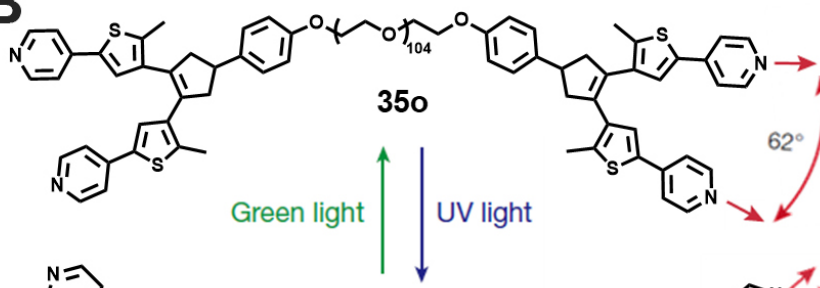

ڤ1)

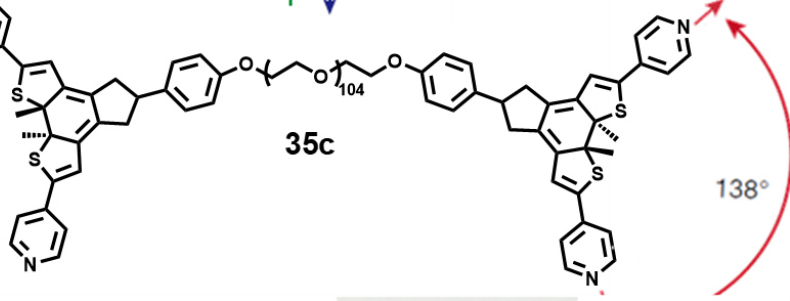

33

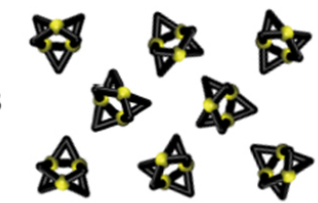

C

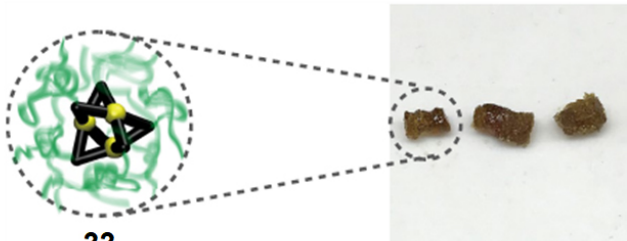

4 hours

at $40^{\circ} \mathrm{C}$

33

fast ligand exchange

UV light

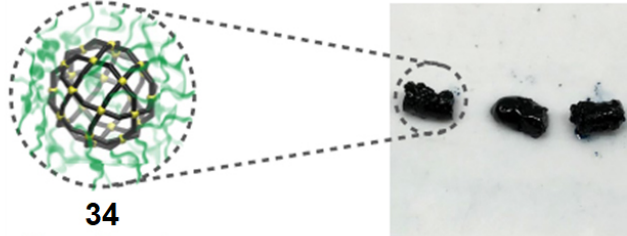

Green light $\uparrow$ UV light

4 hours

at $40^{\circ} \mathrm{C}$

slow ligand exchange

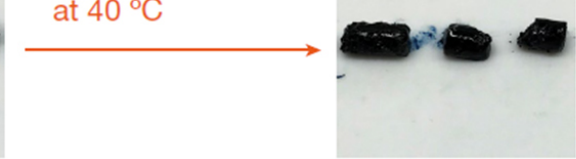

Green light $\uparrow$ UV light

34

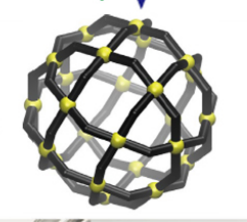

c-gel (non-healable)

o-gel (self-healable)

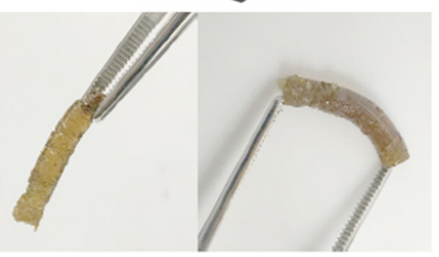

(
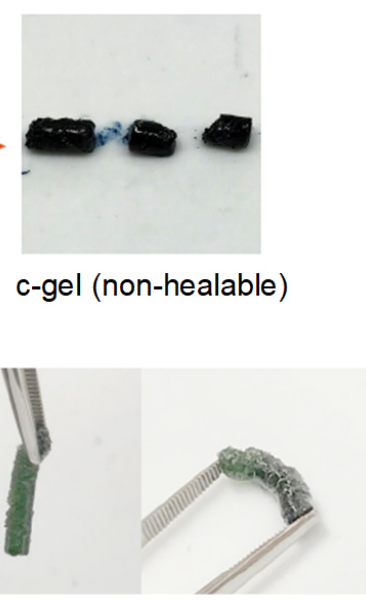

o-gel (self-healable)

fast ligand exchange

Figure 11. (A) Schematic illustration of light-induced structural interconversion between two different network topologies. (B) Chemical structure of the photoresponsive polymer ligand 35. (C) Photographs of self-healing experiments of the polymer gel (o-gel and c-gel). This figure is used with permission from Gu et al. ${ }^{[43]}$.

closed shell singlet state than $\mathrm{Fe}^{2+}{ }_{2}(\mathbf{3 8 0})_{3}$, further demonstrating their structural difference. In addition, a tetranuclear square complex $\mathrm{Fe}^{3+}{ }_{2} \mathrm{Fe}^{2+}{ }_{2}(\mathbf{3 8 0})_{2}$ was obtained through reaction of the ligand 380 with $\mathrm{Fe}(\mathrm{OTf})_{2}$ 


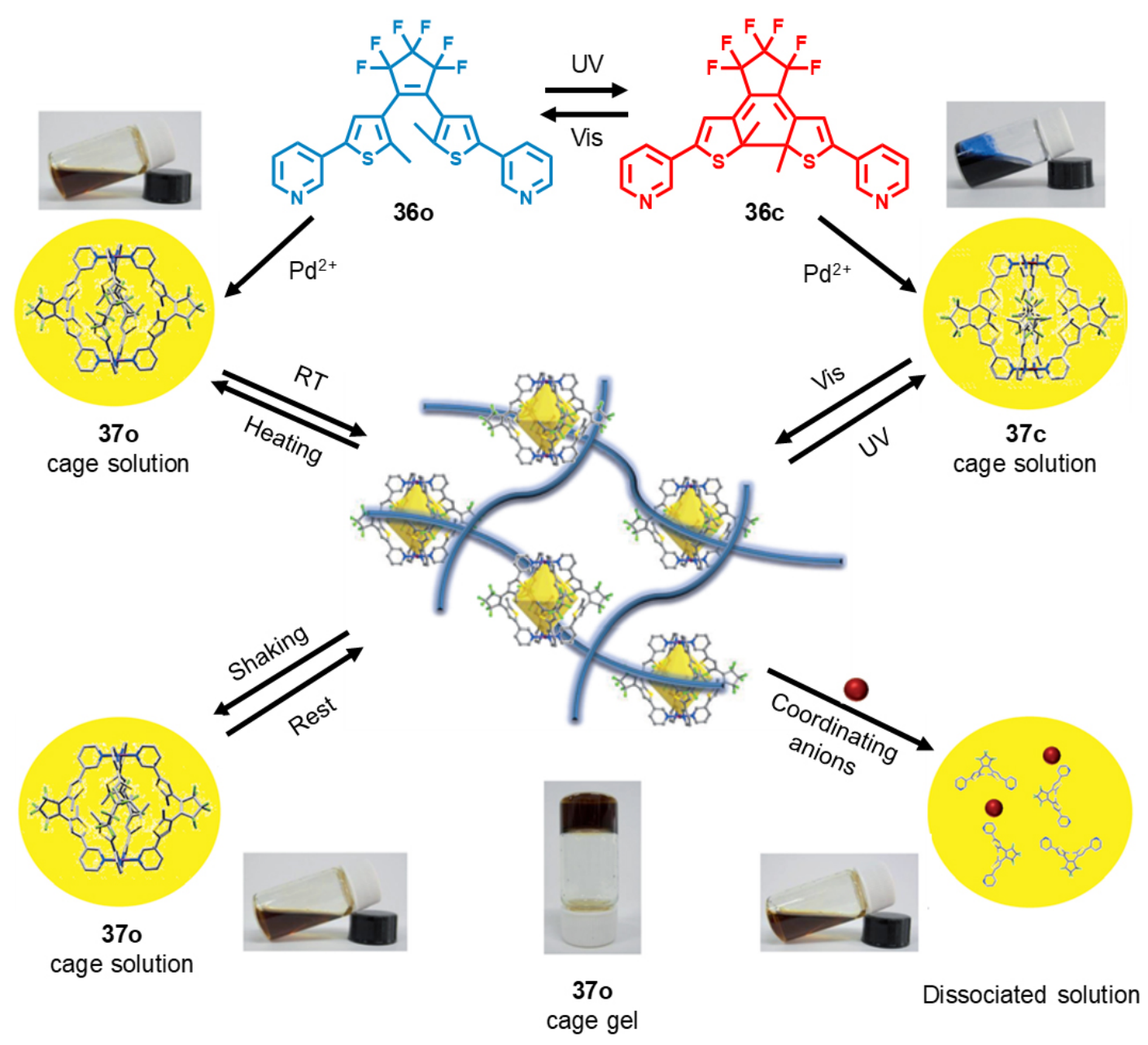

Figure 12. The multi-stimuli-responsive behavior of the metallacage 37. This figure is used with permission from Wei et al. ${ }^{[44]}$.

and $(\mathrm{TEA})\left[\mathrm{Fe}^{\mathrm{III}}\left(\mathrm{Tp}^{*}\right)(\mathrm{CN})_{3}\right] \cdot \mathrm{H}_{2} \mathrm{O}$ at $320 \mathrm{~K}$. X-ray crystal of $\mathrm{Fe}^{3+}{ }_{2} \mathrm{Fe}^{2+}{ }_{2}(380){ }_{2}$ revealed the parallel conformation of diarylethenes, which was photoinactive under UV irradiation. Moreover, the average of length of $\mathrm{Fe}-\mathrm{N}$ bond in $\mathrm{Fe}^{3+}{ }_{2} \mathrm{Fe}^{2+}{ }_{2}(\mathbf{3 8 0})_{2}$ was 1.957 and $1.965 \AA$ at 100 and $295 \mathrm{~K}$, respectively, indicating its LS Fe $\mathrm{FI}^{\mathrm{II}}$ state. It should be noted that $\mathrm{Fe}^{2+}{ }_{2}(380)_{3}$ and $\mathrm{Fe}^{2+}{ }_{2}(38 \mathrm{C})_{3}$ could transform into $\mathrm{Fe}^{3+}{ }_{2} \mathrm{Fe}^{2+}{ }_{2}(380){ }_{2}$ with the addition of $\left[\mathrm{Fe}^{\mathrm{III}}\left(\mathrm{Tp}^{*}\right)(\mathrm{CN})_{3}\right]^{-}$at $320 \mathrm{~K}$. This finding demonstrates that $\mathrm{Fe}^{2+}{ }_{2}(\mathbf{3 8 0})_{3}$ was dynamically stable, while $\mathrm{Fe}^{3+}{ }_{2} \mathrm{Fe}^{2+}{ }_{2}(\mathbf{3 8 0})_{2}$ was thermodynamically stable. Furthermore, the magnetic properties of these three metallacages were investigated by superconducting quantum interference device (SQUID) experiments. The results indicate that $\mathrm{Fe}^{2+}{ }_{2}(\mathbf{3 8 0})_{3}$ was diamagnetic when the temperature was lower than $400 \mathrm{~K}$ and $\mathrm{Fe}^{2+}{ }_{2}(38 \mathrm{c})_{3}$ showed paramagnetism and incomplete spin-crossover behavior (30\% high-spin). $\mathrm{Fe}^{3+}{ }_{2} \mathrm{Fe}^{2+}{ }_{2}(380){ }_{2}$ exhibited paramagnetism and complete spin-crossover behavior with a spin-transition temperature at about $353 \mathrm{~K}$, corresponding to the results from variable-temperature IR and ${ }^{57} \mathrm{Fe}$ Mössbauer spectra. In addition, experiments on cyclic voltammetry measurements indicated both $\mathrm{Fe}^{2+}{ }_{2}(380)_{3}$ and $\mathrm{Fe}^{3+}{ }_{2} \mathrm{Fe}^{2+}{ }_{2}(380)_{2}$ showed extremely high electrochemical stabilities. This study realized the construction of diarylethene-based metallacages with switchable magnetism, which is very helpful for developing SCCs for molecular magnetic devices in the future. 

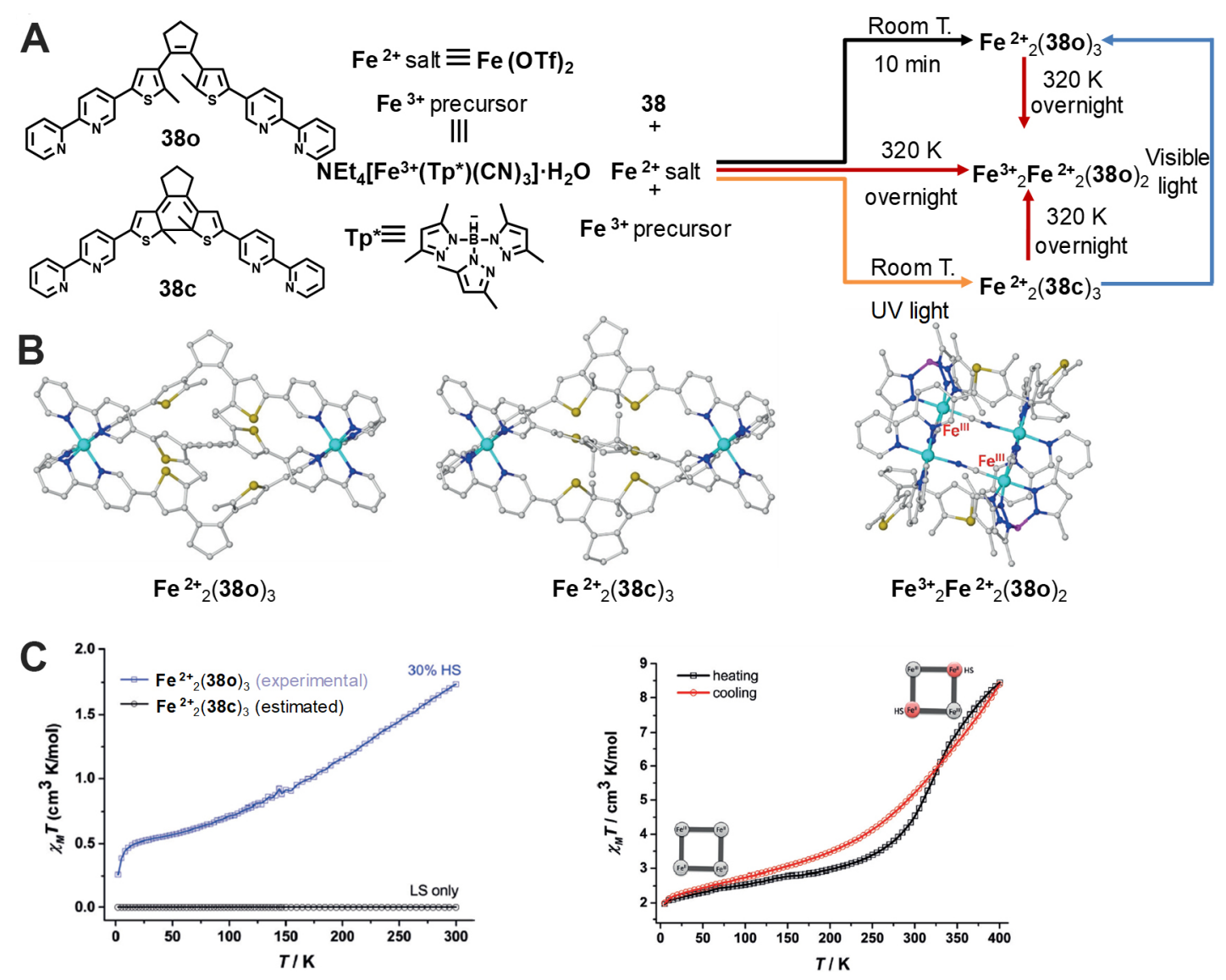

Figure 13. (A) Synthetic routes of the metallacages form the diarylethene ligands 380 and $38 \mathrm{c}$. (B) Crystal structures of $\mathrm{Fe}^{2+}{ }_{2}(380)_{3}$ and $\mathrm{Fe}^{3+}{ }_{2} \mathrm{Fe}_{2}{ }_{2}(380)_{2}$ and optimized structures of $\mathrm{Fe}_{2}^{2+}(38 \mathrm{c})_{3}$. (C) Magnetic properties of three metallacages. This figure is used with permission from Li et al. ${ }^{[45]}$.

Rare-earth metals can also be used to construct SCCs. In 2018, Cai et al. ${ }^{[46]}$ reported the construction of a chiral diarylethene-based metallacage via Eu coordination and studied its photochromic behavior. As shown in Figure 14, by reacting of the diarylethene-containing chiral ligand 39 with $\mathrm{Eu}\left(\mathrm{ClO}_{4}\right)_{3} \cdot 6 \mathrm{H}_{2} \mathrm{O}$ in a $3: 2$ ratio in $\mathrm{CH}_{3} \mathrm{CN}$, the $\mathrm{Eu}_{2} \mathrm{~L}_{3}$ helicate 400 was obtained quantitatively, which was well characterized with NMR and ESI-TOF-MS spectra. In particular, CD experiments disclosed that the helicates showed extremely strong CD signals as compared to the weak CD signal of the ligands, which was ascribed to the chirality induction from the strong cooperative mechanical coupling effects within the helicates. DFT calculations revealed that the point-chirality of the ligands could be transferred to metal centers, which further led to the formation of helical chirality. In addition, the helicate showed excellent photochromic properties under light irradiation and the ring-closed form helicate also showed strong CD signals. However, stereocontrolled ring closure of the helicates failed, probably due to their relatively flexible structures, which resulted in fast ligand exchanges within the helicates. Moreover, the helicate exhibited a photoswitchable luminescence property. The luminescence of the typical Eu complex at $615 \mathrm{~nm}$ was enhanced under UV irradiation, thus offering an opportunity to develop erasable molecular devices.

Subcomponent self-assembly is an important method for constructing multifunctional SCCs. Recently, Zhang et al. ${ }^{[47]}$ constructed a series of diarylethene-based metallacages via subcomponent self-assembly, which was then reduced to pure covalent-organic cages, and investigated their photochromic behavior and applications in multi-readout logic gate systems. As shown in Figure 15, the metallacages 440-460 were 
A
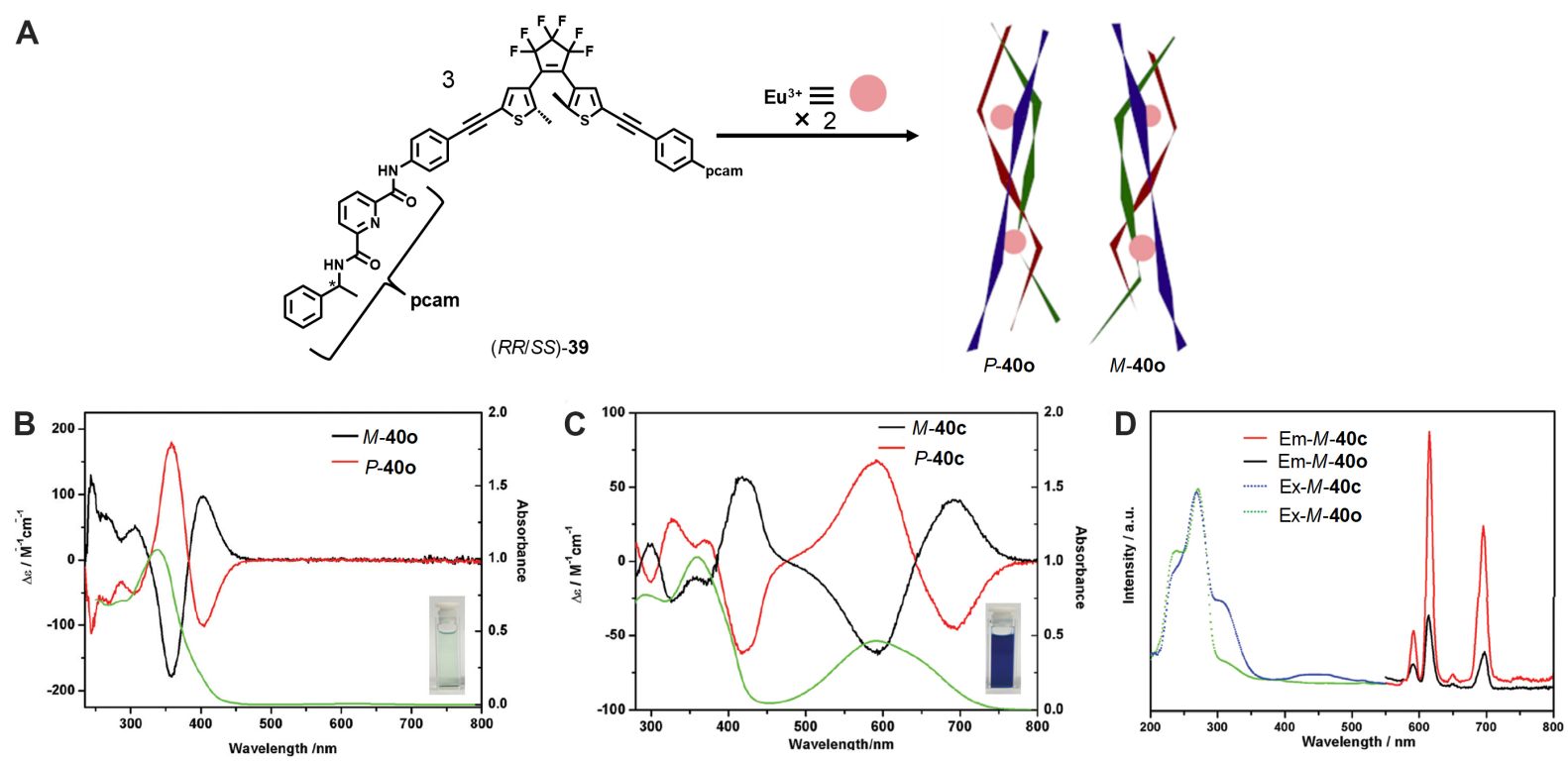

Figure 14. (A) Synthesis of the helicates $P-400$ and $M-400$. CD spectra of $P-400$ and $M-40 o$ (B) and $P-40 c$ and $M-40 c$ (C). (D) Excitation and emission spectra of the helicates. This figure is used with permission from Cai et al. ${ }^{[46]}$.

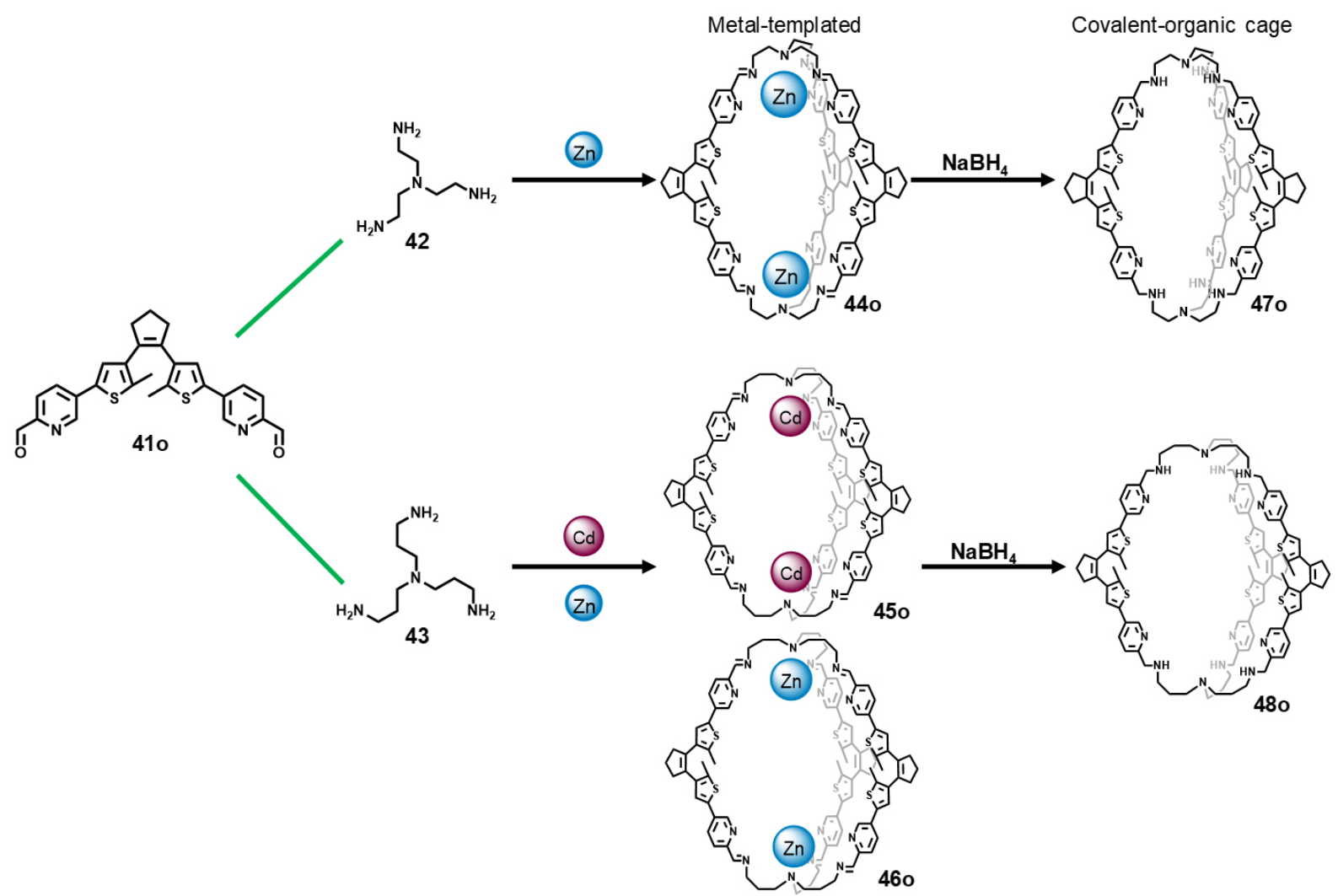

Figure 15. Synthesis route of a series of metallacages $440-460$ via subcomponent self-assembly and subsequent reduction into covalent-organic cages $\mathbf{4 7 0}$ and $\mathbf{4 8 0}$.

obtained through the reaction of $\mathbf{4 1 0}$, tris(2-aminoethyl) amine (42) and $\mathrm{Zn}(\mathrm{OTf})_{2}$ or $\mathrm{Cd}(\mathrm{OTf})_{2}$ in $\mathrm{CH}_{3}$ $\mathrm{CN} / \mathrm{CHCl}_{3}$. X-ray crystal structures disclosed that the metallacages both adopted triple-helicate structures 
with larger cavities for $\mathbf{4 5 0}$ and $\mathbf{4 6 0}$. Further experiments on UV-Vis absorption spectra and NMR spectra demonstrated that the efficient photochromism could occur within the metallacages 440-46o, but only one diarylethene subunit could be converted into the ring-closed form due to the spatial hindrance in the metallacages. Furthermore, the metallacages were reduced and demetalated with $\mathrm{NaBH}_{4}$ to afford the covalent-organic cages $\mathbf{4 7 0}$ and $\mathbf{4 8 0}$, which showed similar photochromic properties to the metallacages (only one diarylethene subunit could be converted into the ring-closed form). It should be noted that the photoisomerization dynamic rates from the ring-open form to ring-closed form of metallacages $\mathbf{4 4 0 - 4 6 0}$ and organic cages $\mathbf{4 7 0}$ and $\mathbf{4 8 0}$ were largely decreased as compared to the ligand $\mathbf{4 1 0}$, due to the steric hindrance of the cage structure. Host/guest test of the resultant covalent cages indicated that they could bind $\mathrm{HSO}_{4}^{-}$or $\mathrm{H}_{2} \mathrm{PO}_{4}^{-}$anions through hydrogen bonding. The addition of anions decreased the photoconversion yield because of the restricted diarylethene skeletons. Furthermore, the metallacages and organic cages were doped with rare earth upconversion materials to form hybrid materials, and the hybrid materials exhibited potential for multi-readout logic gate applications.

\section{CONCLUSION AND OUTLOOK}

In summary, during the past few years, various diarylethene-based SCCs including metallacycles and metallacages were successfully constructed, some of which presented very interesting photophysical and photochemical property. Firstly, when diarylethene subunits were employed as the backbones within the metallacycles and metallacages, the formation of metallacycles and metallacages could immobilize the conformations of the diarylethene subunits, thus leading to a great impact on the photochromic properties of the metallacages such as the photoconversion yield, photoreaction rate and fatigue-resistant property. Secondly, due to different geometrical structures of the ring-open form and ring-closed form diarylethenes, the structures of the metallacycles and metallacages showed relative size changes under light irradiation, which could be applicated in photoresponsive guest encapsulation/release, light-induced chirality switching and photo-controlled topology transformation within polymer networks. In addition, diarylethene and other functional subunits could be integrated into one metallacycle or metallacage. The well-defined shapes and sizes of the metallacycles or metallacages led to efficient intramolecular interactions between the different subunits, thus offering an opportunity for switchable luminescence and controlled generation of ${ }^{1} \mathrm{O}_{2}$.

Despite the unique properties and functions of the diarylethene-based metallacycles and metallacages, some important issues need to be solved in this area. For instance, as for the photoresponsive guest encapsulation/release of diarylethene-based metallacycles and metallacages, the scope of the guest was very limited due to the small cavity of the metallacage. In addition, the photochromic property was inhibited within the metallacycles or metallacages due to steric hindrance to some extent, especially for the metallacycles and metallacages with small size. Hence, some improvement should be taken into consideration for further developing diarylethene-based metallacycles and metallacages. On the one hand, additional non-covalent interactions such as hydrogen bond and $\pi-\pi$ interaction could be involved into the metallacycles and metallacages to enhance their affinity for more neutral and cationic guests. On the other hand, the diarylethene ligands should be designed reasonably (e.g., lengthen the ligands) to decrease the steric hindrance within the metallacycles and metallacages, further benefiting their photochromism. The diarylethene-based metallacycles and metallacages with enhanced photochromic property could be applied in artificial machines and smart materials. In conclusion, diarylethene-based metallacycles and metallacages will gain increasing attention and play a more important role in supramolecular chemistry and materials science in the future. 


\section{DECLARATIONS}

\section{Acknowledgments}

We greatly appreciate Li-Jun Chen and Shangjun Chen for their generous help with the manuscript preparation.

\section{Authors' contributions}

Prepared the manuscript: Qin Y, Wang YT

Performed manuscript correcting: Yang HB, Zhu W

Qin Y and Wang YT contributed equally in this article.

\section{Availability of data and materials}

Not applicable.

\section{Financial support and sponsorship}

Yang HB acknowledges the financial support of Innovation Program of Shanghai Municipal Education Commission (No. 2019-01-07-00-05-E00012), and the Program for Changjiang Scholars and Innovative Research Team in University. Zhu W thanks the financial support from NSFC Science Center Program (21788102) and NSFC/China (21974047 and 21622602).

\section{Conflicts of interest}

All authors declared that there are no conflicts of interest.

\section{Ethical approval and consent to participate}

Not applicable.

\section{Consent for publication}

Not applicable.

\section{Copyright}

(c) The Author(s) 2021.

\section{REFERENCES}

1. Fujita M, Tominaga M, Hori A, Therrien B. Coordination assemblies from a Pd(II)-cornered square complex. Acc Chem Res 2005;38:369-78. DOI PubMed

2. Cook TR, Stang PJ. Recent Developments in the preparation and chemistry of metallacycles and metallacages via coordination. Chem Rev 2015;115:7001-45. DOI PubMed

3. Zhang D, Ronson TK, Nitschke JR. Functional capsules via subcomponent self-assembly. Acc Chem Res 2018;51:2423-36. DOI PubMed

4. Gao WX, Feng HJ, Guo BB, Lu Y, Jin GX. Coordination-directed construction of molecular links. Chem Rev 2020;120:6288-325. DOI PubMed

5. Chen LJ, Yang HB, Shionoya M. Chiral metallosupramolecular architectures. Chem Soc Rev 2017;46:2555-76. DOI PubMed

6. Pullen S, Clever GH. Mixed-ligand metal-organic frameworks and heteroleptic coordination cages as multifunctional scaffolds-A comparison. Acc Chem Res 2018;51:3052-64. DOI PubMed PMC

7. Wang H, Li Y, Li N, Filosa A, Li X. Increasing the size and complexity of discrete 2D metallosupramolecules. Nat Rev Mater 2021;6:145-67. DOI

8. Pan M, Wu K, Zhang J, Su C. Chiral metal-organic cages/containers (MOCs): from structural and stereochemical design to applications. Coord Chem Rev 2019;378:333-49. DOI

9. Cullen W, Misuraca MC, Hunter CA, Williams NH, Ward MD. Highly efficient catalysis of the Kemp elimination in the cavity of a cubic coordination cage. Nat Chem 2016;8:231-6. DOI PubMed

10. Sawada T, Fujita M. Folding and assembly of metal-linked peptidic nanostructures. Chem 2020;6:1861-76. DOI

11. Tessarolo J, Lee H, Sakuda E, Umakoshi K, Clever GH. Integrative assembly of heteroleptic tetrahedra controlled by backbone steric bulk. J Am Chem Soc 2021;143:6339-44. DOI PubMed PMC

12. Kishida N, Matsumoto K, Tanaka Y, Akita M, Sakurai H, Yoshizawa M. Anisotropic contraction of a polyaromatic capsule and its cavity-induced compression effect. J Am Chem Soc 2020;142:9599-603. DOI PubMed 
13. Howlader P, Mondal S, Ahmed S, Mukherjee PS. Guest-induced enantioselective self-assembly of a Pd6 homochiral octahedral cage with a C3-symmetric pyridyl donor. J Am Chem Soc 2020;142:20968-72. DOI PubMed

14. Ma L, Haynes CJE, Grommet AB, et al. Coordination cages as permanently porous ionic liquids. Nat Chem 2020;12:270-5. DOI PubMed

15. Mu C, Zhang Z, Hou Y, et al. Tetraphenylethylene-based multicomponent emissive metallacages as solid-state fluorescent materials. Angew Chem Int Ed Engl 2021;60:12293-7. DOI PubMed

16. Jia PP, Xu L, Hu YX, et al. Orthogonal self-assembly of a two-step fluorescence-resonance energy transfer system with improved photosensitization efficiency and photooxidation activity. J Am Chem Soc 2021;143:399-408. DOI PubMed

17. Gao W, Zhang H, Jin G. Supramolecular catalysis based on discrete heterometallic coordination-driven metallacycles and metallacages. Coord Chem Rev 2019;386:69-84. DOI

18. Chen LJ, Yang HB. Construction of stimuli-responsive functional materials via hierarchical self-assembly involving coordination interactions. Acc Chem Res 2018;51:2699-710. DOI PubMed

19. Zheng W, Yang G, Shao N, et al. $\mathrm{CO}_{2}$ stimuli-responsive, injectable block copolymer hydrogels cross-linked by discrete organoplatinum(II) metallacycles via stepwise post-assembly polymerization. J Am Chem Soc 2017;139:13811-20. DOI PubMed

20. Cai LX, Yan DN, Cheng PM, et al. Controlled self-assembly and multistimuli-responsive interconversions of three conjoined twincages. J Am Chem Soc 2021;143:2016-24. DOI PubMed

21. Zhang Z, Zhao Z, Wu L, et al. Emissive Platinum(II) cages with reverse fluorescence resonance energy transfer for multiple sensing. $J$ Am Chem Soc 2020;142:2592-600. DOI PubMed PMC

22. Huang SL, Hor TA, Jin GX. Photodriven single-crystal-to-single-crystal transformation. Coord Chem Rev 2017;346:112-22. DOI

23. Zhang Q, Tang D, Zhang J, et al. Self-healing heterometallic supramolecular polymers constructed by hierarchical assembly of triply orthogonal interactions with tunable photophysical properties. J Am Chem Soc 2019;141:17909-17. DOI PubMed PMC

24. Irie M, Fukaminato T, Matsuda K, Kobatake S. Photochromism of diarylethene molecules and crystals: memories, switches, and actuators. Chem Rev 2014;114:12174-277. DOI PubMed

25. Hou L, Leydecker T, Zhang X, et al. Engineering optically switchable transistors with improved performance by controlling interactions of diarylethenes in polymer matrices. J Am Chem Soc 2020;142:11050-9. DOI PubMed

26. Hnid I, Frath D, Lafolet F, Sun X, Lacroix JC. Highly efficient photoswitch in diarylethene-based molecular junctions. J Am Chem Soc 2020;142:7732-6. DOI PubMed

27. Liu G, Zhu J, Zhou Y, Dong Z, Xu X, Mao P. Adjustable photochromic behavior of a diarylethene-based bistable [3]Rotaxane. Org Lett 2018;20:5626-30. DOI PubMed

28. Wezenberg SJ. Light-switchable Metal-Organic Cages. Chem Lett 2020;49:609-15. DOI

29. Murguly E, Norsten TB, Branda NR. Nondestructive data processing based on chiroptical 1,2-dithienylethene photochromes. Angew Chem Int Ed 2001;40:1752-5. PubMed

30. Chen S, Chen LJ, Yang HB, Tian H, Zhu W. Light-triggered reversible supramolecular transformations of multi-bisthienylethene hexagons. J Am Chem Soc 2012;134:13596-9. DOI PubMed

31. Cook TR, Zheng YR, Stang PJ. Metal-organic frameworks and self-assembled supramolecular coordination complexes: comparing and contrasting the design, synthesis, and functionality of metal-organic materials. Chem Rev 2013;113:734-77. DOI PubMed PMC

32. Li M, Chen LJ, Zhang Z, et al. Conformer-dependent self-assembled metallacycles with photo-reversible response. Chem Sci 2019;10:4896-904. DOI PubMed PMC

33. Li M, Chen LJ, Cai Y, et al. Light-driven chiral switching of supramolecular metallacycles with photoreversibility. Chem 2019;5:63448. DOI

34. Wang YX, Zhou QF, Jiang ST, et al. Photoresponsive chirality-tunable supramolecular metallacycles. Macromol Rapid Commun 2018;39:e1800454. DOI PubMed

35. Qin Y, Zhang Y, Yin G, et al. Construction of highly emissive Pt(II) metallacycles upon irradiation. Chin J Chem 2019;37:323-9. DOI

36. Qin Y, Chen LJ, Zhang Y, et al. Photoswitchable Förster resonance energy transfer (FRET) within a heterometallic Ir-Pt macrocycle. Chem Commun (Camb) 2019;55:11119-22. DOI PubMed

37. Qin Y, Chen LJ, Dong F, et al. Light-controlled generation of singlet oxygen within a discrete dual-stage metallacycle for cancer therapy. J Am Chem Soc 2019;141:8943-50. DOI PubMed

38. Han M, Michel R, He B, et al. Light-triggered guest uptake and release by a photochromic coordination cage. Angew Chem Int Ed Engl 2013;52:1319-23. DOI PubMed

39. Han M, Luo Y, Damaschke B, et al. Light-controlled interconversion between a self-assembled triangle and a rhombicuboctahedral sphere. Angew Chem Int Ed Engl 2016;55:445-9. DOI PubMed

40. Li RJ, Han M, Tessarolo J, et al. Successive photoswitching and derivatization effects in photochromic dithienylethene-based coordination cages. ChemPhotoChem 2019;3:378-83. DOI

41. Li RJ, Holstein JJ, Hiller WG, Andréasson J, Clever GH. Mechanistic interplay between light switching and guest binding in photochromic [Pd2Dithienylethene4] coordination cages. J Am Chem Soc 2019;141:2097-103. DOI PubMed

42. Li RJ, Tessarolo J, Lee H, Clever GH. Multi-stimuli control over assembly and guest binding in Metallo-supramolecular hosts based on dithienylethene photoswitches. J Am Chem Soc 2021;143:3865-73. DOI PubMed PMC

43. Gu Y, Alt EA, Wang H, Li X, Willard AP, Johnson JA. Photoswitching topology in polymer networks with metal-organic cages as crosslinks. Nature 2018;560:65-9. DOI PubMed

44. Wei SC, Pan M, Fan YZ, Liu H, Zhang J, Su CY. Creating coordination-based cavities in a multiresponsive supramolecular gel. Chemistry 2015;21:7418-27. DOI PubMed 
45. Li ZY, Dai JW, Damjanović M, et al. Structure switching and modulation of the magnetic properties in diarylethene-bridged metallosupramolecular compounds by controlled coordination-driven self-assembly. Angew Chem Int Ed Engl 2019;58:4339-44. DOI PubMed

46. Cai LX, Yan LL, Li SC, Zhou LP, Sun QF. Stereocontrolled self-assembly and photochromic transformation of lanthanide supramolecular helicates. Dalton Trans 2018;47:14204-10. DOI PubMed

47. Zhang JH, Wang HP, Zhang LY, et al. Coordinative-to-covalent transformation, isomerization dynamics, and logic gate application of dithienylethene based photochromic cages. Chem Sci 2020;11:8885-94. DOI PubMed PMC 